\title{
Light absorption by marine cyanobacteria affects tropical climate mean state and variability
}

\author{
Hanna Paulsen, Tatiana Ilyina, Johann H. Jungclaus, Katharina D. Six, and Irene Stemmler \\ Max Planck Institute for Meteorology, Hamburg, Germany \\ Correspondence: Hanna Paulsen (hanna.paulsen@mpimet.mpg.de)
}

Received: 28 August 2018 - Discussion started: 4 September 2018

Revised: 23 November 2018 - Accepted: 27 November 2018 - Published: 5 December 2018

\begin{abstract}
Observations indicate that positively buoyant marine cyanobacteria, which are abundant throughout the tropical and subtropical ocean, have a strong local heating effect due to light absorption at the ocean surface. How these local changes in radiative heating affect the climate system on the large scale is unclear. We use the Max Planck Institute Earth System Model (MPI-ESM), include light absorption by cyanobacteria, and find a considerable cooling effect on tropical sea surface temperature (SST) in the order of $0.5 \mathrm{~K}$ on a climatological timescale. This cooling is caused by local shading of subtropical subsurface water by cyanobacteria that is upwelled at the Equator and in eastern boundary upwelling systems. Implications for the climate system include a westward shift of the Walker circulation and a weakening of the Hadley circulation. The amplitude of the seasonal cycle of SST is increased in large parts of the tropical ocean by up to $25 \%$, and the tropical Pacific interannual variability is enhanced by approx. $20 \%$. This study emphasizes the sensitivity of the tropical climate system to light absorption by cyanobacteria due to its regulative effect on tropical SST. Generally, including phytoplankton-dependent light attenuation instead of a globally uniform attenuation depth improves some of the major model temperature biases, indicating the relevance of taking this biophysical feedback into account in climate models.
\end{abstract}

\section{Introduction}

Phytoplankton pigments, predominantly chlorophyll $a(\mathrm{Chl})$, absorb light and thereby modify the vertical distribution of radiative heating in the upper ocean (e.g., Lewis et al., 1990; Strutton and Chavez, 2004). Numerous model studies, using ocean-only and coupled climate models, indicate that the biologically induced redistribution of heat in the water column considerably affects ocean temperature and circulation (e.g., Murtugudde et al., 2002; Manizza et al., 2008; Löptien et al., 2009) with implications for climate mean state and variability (e.g., Wetzel et al., 2006; Anderson et al., 2007; Patara et al., 2012). In this study, we specifically investigate the effects of light absorption by the phytoplankton group of positively buoyant marine cyanobacteria on the tropical climate system.

Positively buoyant marine cyanobacteria are observed by in situ and satellite measurements to have a particularly strong local heating effect on sea surface temperature (SST) by up to 0.95-5.0 K (Kahru et al., 1993; Capone et al., 1998; Wurl et al., 2018). Cyanobacteria are abundant throughout the tropical and subtropical ocean, where they often represent a dominant fraction of total phytoplankton biomass (e.g., Carpenter and Romans, 1991; Capone et al., 1997; Luo et al., 2012). The unique capability of cyanobacteria to fix nitrogen gas $\left(\mathrm{N}_{2}\right)$ enables them to grow within and at the edges of the nitrate-depleted subtropical gyres (e.g., Luo et al., 2012). Positively buoyant cyanobacteria have the capacity to form large surface blooms extending up to several million square kilometers (e.g., Capone et al., 1998). Although the chlorophyll content of cyanobacteria is in general rather low compared to that of other phytoplankton (e.g., Berman-Frank et al., 2001; Carpenter et al., 2004; Sathyendranath et al., 2009), the dense accumulations of biomass in cyanobacteria blooms result in high chlorophyll concentrations (e.g., Subramaniam et al., 2001; Westberry and Siegel, 2006) and hence strong light absorption and heat trapping at the ocean surface. 
The observed strong effect of cyanobacteria on the local vertical thermal structure of the water column is supported by one-dimensional and regional model studies of the Baltic Sea and the North Atlantic Ocean (Hense, 2007; Sonntag and Hense, 2011; Sonntag, 2013). In these studies, positively buoyant cyanobacteria lead to a local heating effect of up to $2 \mathrm{~K}$ and a mixed layer depth (MLD) shoaling of up to $20 \mathrm{~m}$. These changes in the physical environment regionally promote growth of cyanobacteria, constituting a positive feedback loop between ocean biology and physics.

The existing observational and model studies give evidence for the importance of light absorption by cyanobacteria for the physical environment. But these studies are only representative on a local, or at best regional, scale. All global model studies dealing with the feedback from phytoplankton on ocean temperature, however, only consider the effect of light absorption by phytoplankton in general, without differentiating between individual phytoplankton groups (e.g., Patara et al., 2012, and references therein). Moreover, none of the biogeochemical models used in these global studies contain positively buoyant cyanobacteria. Cyanobacteria are, however, abundant throughout large parts of the tropical and subtropical ocean. In these areas, and more precisely within and at the margins of the subtropical gyres, light absorption by marine biota was proposed to particularly affect tropical SST and the climate system (Anderson et al., 2007, 2009; Gnanadesikan and Anderson, 2009). By using a modified satellite chlorophyll climatology in which chlorophyll is set to zero in distinct regions, these studies showed that the presence of chlorophyll in the respective regions strongly affects the oceanic and atmospheric large-scale circulation, as well as tropical Pacific interannual variability. Given that cyanobacteria are a dominant phytoplankton group in these regions of the ocean, the open question is the following. Do cyanobacteria affect their environment not only locally, as indicated by previous studies, but also play a role in the climate system on a more global scale?

We therefore investigate the interactive feedback from light absorption by cyanobacteria on the large-scale tropical climate system. We use the Max Planck Institute Earth System Model (MPI-ESM), which was recently extended by a realistic representation of positively buoyant $\mathrm{N}_{2}$-fixing cyanobacteria (Paulsen et al., 2017). We include cyanobacteria, in addition to bulk phytoplankton, in affecting the shortwave radiation attenuation depth. By setting the chlorophyll content of cyanobacteria to zero, we separate the effects induced by cyanobacteria from those induced by bulk phytoplankton, and address the following questions. (1) How does the local redistribution of heat by cyanobacteria affect the large-scale ocean temperature distribution and the climate mean state, such as ocean and atmosphere general circulation? (2) What are the effects on climate variability, such as seasonal variability of SST and tropical Pacific interannual variability in SST? (3) How do the changes in ocean temperature and circulation feed back on phytoplankton growth itself? (4) What are the positive or negative feedbacks at play? By varying the chlorophyll content per cyanobacteria biomass (and thereby the strength of light absorption), we get a better understanding of the underlying processes and can assess the sensitivity of the results to this parameter. We furthermore compare the model results against a model state with phytoplankton-independent (globally uniform) light attenuation. We discuss the results in the context of model biases and in the context of previous model studies, and indicate implications for the Earth system model.

\section{Model description and experimental setup}

\subsection{The MPI-ESM}

We use MPI-ESM1.2, which consists of the coupled general circulation models for the atmosphere ECHAM (Stevens et al., 2013) and the ocean MPIOM (Jungclaus et al., 2013), the ocean biogeochemistry model HAMOCC (Ilyina et al., 2013) extended by prognostic $\mathrm{N}_{2}$-fixing cyanobacteria (Paulsen et al., 2017), and the land surface and terrestrial biosphere model including dynamic vegetation JSBACH (Reick et al., 2013; Schneck et al., 2013). The explicit model versions are ECHAM6.3.02p2, MPIOM1.6.2p2, HAMOCC5.2, JSBACH3.10, which are further developments of the models described in the references above.

We apply a grid configuration referred to as LR (GR15 for MPIOM, T63L47 for ECHAM6). In the atmosphere, the horizontal resolution is T63 in spectral space (approx. $1.75^{\circ}$ on a Gaussian grid) with 47 vertical $\sigma$-hybrid layers. The time step is $450 \mathrm{~s}$. In the ocean, the bipolar grid GR15 has poles over Antarctica and Greenland and a horizontal resolution of approx. $1.5^{\circ}$, gradually varying between $15 \mathrm{~km}$ in the Arctic and about $184 \mathrm{~km}$ in the tropics. In the vertical, there are 40 unevenly spaced layers with level thicknesses increasing with depth and 9 layers located within the upper $90 \mathrm{~m}$. The time step is $2700 \mathrm{~s}$. MPIOM is a $z$-coordinate global general circulation model solving the primitive equations under the hydrostatic and Boussinesq approximation on a C-grid with a free surface (Marsland et al., 2003; Jungclaus et al., 2013). Momentum, heat, and freshwater fluxes are coupled daily between ECHAM and MPIOM using the Ocean Atmosphere Sea Ice Soil (OASIS3-MCT; Valcke, 2013) coupler.

The global ocean biogeochemistry model HAMOCC serves to simulate carbon cycling in the ocean. The spatial and temporal resolutions of HAMOCC are inherited from MPIOM. HAMOCC includes biogeochemical processes in the water column, the sediment, and gas-exchange processes at the air-sea interface. Biogeochemical tracers in the water column are fully advected, mixed, and diffused by the flow field of the physical model. Biogeochemistry dynamics are premised on an extended NPZD (Nutrients, Phytoplankton, Zooplankton, Detritus) model approach (Six and Maier-Reimer, 1996), and include phosphate, nitrate, iron, oxygen, silicate, opal, calcium carbon- 
ate, dissolved inorganic carbon, alkalinity, two phytoplankton groups, zooplankton, dissolved organic matter, and detritus. Organic material composition follows a constant molar ratio $\left(\mathrm{C}: \mathrm{N}: \mathrm{P}: \mathrm{O}_{2}=122: 16: 1:-172\right)$ based on Takahashi et al. (1985) and of iron $\left(\mathrm{Fe}: \mathrm{P}=366 \times 10^{-6}: 1\right)$ based on Johnson et al. (1997).

Phytoplankton is represented by two tracers in the model, $\mathrm{N}_{2}$-fixing cyanobacteria (Cya) and bulk phytoplankton (Phy). The growth parameterization of cyanobacteria is based on physiological characteristics of Trichodesmium (Paulsen et al., 2017), a positively buoyant cyanobacteria group that is considered as one of the most important marine diazotrophs (e.g., LaRoche and Breitbarth, 2005). Cyanobacteria fix $\mathrm{N}_{2}$ under nitrate depletion but can also take up nitrate, when available. Furthermore, cyanobacteria are positively buoyant with a rising velocity of $1 \mathrm{~m} \mathrm{day}^{-1}$ (based on Sonntag, 2013), in contrast to bulk phytoplankton, which are neutrally buoyant. Growth of cyanobacteria occurs within a specific optimum temperature range described by a modified Gaussian function with an optimum at $28^{\circ} \mathrm{C}$ (Sonntag and Hense, 2011; Breitbarth et al., 2007). For bulk phytoplankton, on the contrary, a power law temperature dependency is applied (Eppley, 1972). Cyanobacteria grow slower than bulk phytoplankton, have a higher iron limitation, and are assumed not to be grazed. A detailed description of the parameterization as well as evaluation of the model performance with respect to cyanobacteria is given in Paulsen et al. (2017).

\subsection{Parameterization of radiative heating in the water column}

Incoming shortwave radiation in the open ocean is attenuated primarily by seawater and by phytoplankton. We use chlorophyll, derived from the phytoplankton concentrations simulated in the biogeochemical model, as a measure of strength of light absorption in the physical model. The vertical light field $I(z)$ is described by the scheme after Zielinski et al. (2002):

$$
\begin{aligned}
I(z) & =I_{0} \cdot f_{\mathrm{vis}} \cdot\left[\sigma \cdot \exp \left(-z \cdot k_{\mathrm{r}}\right)+(1-\sigma)\right. \\
& \left.\cdot \exp \left(-z \cdot k_{\mathrm{w}}-k_{\mathrm{Chl}} \cdot \int_{0}^{z} \operatorname{Chl}\left(z^{\prime}\right) \mathrm{d} z^{\prime}\right)\right] .
\end{aligned}
$$

$I_{0}$ is the daily mean shortwave radiation at sea level calculated by ECHAM and passed once per day to MPIOM. $f_{\text {vis }}$ is the visible light fraction $(0.58)$, which has the potential to penetrate into deeper layers. It covers the wavelength range of $400-700 \mathrm{~nm}$. At $580 \mathrm{~nm}$, the light spectrum is divided (prescribed by $\sigma=0.4$ ) into two domains: for larger wavelengths (red domain) attenuation is dominated by sea water with the attenuation coefficient $k_{\mathrm{r}}\left(0.35 \mathrm{~m}^{-1}\right)$. For shorter wavelengths (blue to green domain) the absorption by chlorophyll with the absorption coefficient $k_{\mathrm{Chl}}$ $\left(0.04 \mathrm{~m}^{2}(\mathrm{mg} \mathrm{Chl})^{-1}\right)$ is considered in addition to clear water with the absorption coefficient $k_{\mathrm{W}}\left(0.03 \mathrm{~m}^{-1}\right)$. The parameter values are adopted from Zielinski et al. (2002). Chlorophyll (Chl) is assumed to be a linear function of bulk phytoplankton and cyanobacteria concentrations:

$\operatorname{Chl}(z)=\frac{1}{R_{\text {Phy }}} \cdot \operatorname{Phy}(z)+\frac{1}{R_{\text {Cya }}} \cdot \operatorname{Cya}(z)$

with $\operatorname{Phy}(z)$ and $\mathrm{Cya}(z)$ being vertical profiles of bulk phytoplankton and cyanobacteria concentrations in carbon units, and $R_{\text {Phy }}$ and $R_{\text {Cya }}$ the respective $\mathrm{C}: \mathrm{Chl}$ ratios in $\mathrm{mgC}(\mathrm{mg} \mathrm{Chl})^{-1}$. Phytoplankton and cyanobacteria concentrations are not only a function of depth $(z)$ but also vary horizontally and temporally, resulting in a temporally and spatially varying chlorophyll field $\operatorname{Chl}(x, y, z, t)$.

Radiative heating of water is accounted for by an internal source of heat in the temperature equation, proportional to the vertical derivative of the light field $I(z)$ :

$\frac{\partial T}{\partial t}=\frac{1}{\rho \cdot c_{\mathrm{p}}} \cdot \frac{\partial I(z)}{\partial z}$

with $\rho$ as the density and $c_{\mathrm{p}}$ the specific heat capacity of seawater. Thereby, it is assumed that the total absorbed light is converted into heat. Biological fluorescence mostly converts into heat, and the absorbed energy stored in biomass is generally small and can be neglected (Lewis et al., 1983, and references therein).

The phytoplankton-dependent light attenuation scheme (Eq. 1) is not part of the default standard model MPIOM (Jungclaus et al., 2013). The standard model version, e.g., used for the fifth phase of the Coupled Model Intercomparison Project (CMIP5), applies a globally uniform exponential profile of light $I(z)$ instead (Paulson and Simpson, 1977):

$I(z)=I_{0} \cdot f_{\text {blue }} \cdot \exp \left(-k_{\text {blue }} \cdot z\right)$.

The attenuation coefficient $k_{\text {blue }}$ of $0.06 \mathrm{~m}^{-1}$ (attenuation depth: $17 \mathrm{~m}$ ) and the blue water fraction $f_{\text {blue }}$ of 0.41 roughly correspond to the Jerlov optical water type 1A (Jerlov, 1976; Kara et al., 2005). The attenuation depth of $17 \mathrm{~m}$ is in the order of magnitude as often used in climate models (Patara et al., 2012, and references therein). Radiative heating is formulated as shown in Eq. (3).

\subsection{Experimental setup}

Three experiments are conducted (Table 1), which all use the phytoplankton-dependent attenuation scheme (Eq. 1). In the first experiment, PHY_ONLY, only light absorption by bulk phytoplankton is accounted for. Cyanobacteria are made transparent with respect to shortwave radiation in the physical model $\left(1 / R_{\text {cya }}=0\right.$ in Eq. 2$)$. For bulk phytoplankton, the $\mathrm{C}:$ Chl ratio is set to $R_{\mathrm{Phy}}=60 \mathrm{mg} \mathrm{C}(\mathrm{mg} \mathrm{Chl})^{-1}$ as is used in HAMOCC (Ilyina et al., 2013). This value lies in the middle of the observed range, which spans values from about 12 to 
Table 1. Experiment names and descriptions.

\begin{tabular}{ll}
\hline Experiment name & Description \\
\hline PHY_ONLY & light absorption by bulk phytoplankton only (cyanobacteria are made transparent) \\
PHY_CYA & light absorption by bulk phytoplankton and cyanobacteria \\
PHY_CYAx2 & light absorption by bulk phytoplankton and cyanobacteria, with doubled chlorophyll content of cyanobacteria \\
CTRL & globally uniform attenuation depth $(17 \mathrm{~m})$ \\
\hline
\end{tabular}

more than $200 \mathrm{mg} \mathrm{C}\left(\mathrm{mg} \mathrm{Chl}^{-1}\right.$, depending on species, light conditions, nutrient limitation, and temperature (e.g., Taylor et al., 1997).

In the second experiment, PHY_CYA, we include cyanobacteria in addition to bulk phytoplankton in affecting the radiative heating in the water column. For cyanobacteria, the C: Chl ratio is set to $R_{\text {Cya }}=120 \mathrm{mg} \mathrm{C}(\mathrm{mg} \mathrm{Chl})^{-1}$. Cyanobacteria generally contain less chlorophyll than other phytoplankton groups (e.g., Berman-Frank et al., 2001; Carpenter et al., 2004). The chosen value lies in the middle of the observed range for Trichodesmium of approx. 40 to

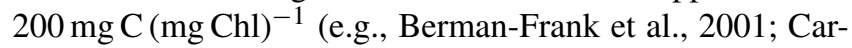
penter et al., 2004).

Finally, because the light absorption strength of cyanobacteria is not well constrained, we consider a sensitivity experiment, PHY_CYAx2. In this experiment, we double the chlorophyll content per cyanobacteria biomass, i.e., setting the value of $R_{\text {Cya }}$ to $60 \mathrm{mg} \mathrm{C}(\mathrm{mg} \mathrm{Chl})^{-1}$, which is the value also applied for bulk phytoplankton. The value lies in the lower range of observed values for Trichodesmium (that means in the upper range of observed chlorophyll content). This experiment allows us to test the sensitivity and linearity of the results to this prescribed parameter, and to assess the upper limit of the effects induced by cyanobacteria light absorption.

The different $\mathrm{C}: \mathrm{Chl}$ ratios for cyanobacteria are only applied for calculating the radiative heating in the physical model. In the biogeochemical model, in all experiments the same self-shading effect is applied for light limitation of photosynthesis for bulk phytoplankton and cyanobacteria $\left(R_{\text {Phy }}=R_{\text {Cya }}=60 \mathrm{mg} \mathrm{C}\left(\mathrm{mg} \mathrm{Chl}^{-1}\right)\right.$ in order to exclude direct effects on cyanobacteria growth.

All three experiments are started from a preindustrial simulation, CTRL, in steady state. CTRL uses the standard model version with globally uniform light attenuation (Eq. 4). All three experiments are integrated for 300 years with prescribed preindustrial atmospheric $\mathrm{CO}_{2}$ volume mixing ratio $(284.7 \mathrm{ppm})$. For all analyses the mean of the last 100 years is evaluated, in which the upper ocean (approx. $500 \mathrm{~m}$ ) shows no considerable drifts in temperature. To assess the added impact on the attenuation depth of shortwave radiation by cyanobacteria, we subtract the mean state PHY_ONLY from PHY_CYA (and PHY_ONLY from PHY_CYAx2, respectively). Furthermore, we compare the model states of the three experiments against CTRL. CTRL spans 800 years and represents an estimate of the internal variability in the model.

\section{Global distribution of cyanobacteria and chlorophyll}

Cyanobacteria occur between $40^{\circ} \mathrm{S}$ and $40^{\circ} \mathrm{N}$ (see Fig. 1 for PHY_CYA) where they constitute an important fraction of total phytoplankton biomass (approx. $18 \%$, locally up to $90 \%$ ). The restriction of cyanobacteria's major habitat to the tropical and subtropical ocean is in agreement with in situ and satellite-based observations (Westberry and Siegel, 2006; Breitbarth et al., 2007; Bracher et al., 2009; Luo et al., 2012). The ecological niche of cyanobacteria is mainly determined by their ability to fix $\mathrm{N}_{2}$, their positive buoyancy, a high optimum temperature of growth, and a strong iron limitation (Paulsen et al., 2017). The global depth-integrated $\mathrm{N}_{2}$ fixation rate of $116.6 \mathrm{Tg} \mathrm{N} \mathrm{yr}^{-1}$ (in PHY_CYA) lies within the range of reported estimates of approx. 80-200 $\mathrm{Tg} \mathrm{N} \mathrm{yr}^{-1}$ (e.g., Karl et al., 2002; Großkopf et al., 2012). The simulated maximum annual mean surface concentrations reach values of approx. $400 \mathrm{mg} \mathrm{C} \mathrm{m}^{-3}$ (depthintegrated approx. $700 \mathrm{mg} \mathrm{C} \mathrm{m}^{-2}$ ), and surface fixation rates of approx. $300 \mu \mathrm{mol} \mathrm{N} \mathrm{m}{ }^{-3}$ day $^{-1}$ (depth-integrated approx. $5000 \mu \mathrm{mol} \mathrm{N} \mathrm{m}{ }^{-2}$ day $^{-1}$ ). The major fraction of biomass and $\mathrm{N}_{2}$ fixation (approx. $85 \%$ ) is located in the upper $20 \mathrm{~m}$. The orders of magnitude of biomass and fixation rates, as well as the large-scale spatiotemporal patterns, are in agreement with observations (Luo et al., 2012). In the North Atlantic subtropical gyre, the model is characterized by an underestimation of cyanobacteria concentrations and $\mathrm{N}_{2}$ fixation rates in comparison to observations. In the eastern tropical Pacific, on the other hand, concentrations and fixation rates are high, but the lack of observational data does not allow for a proper assessment. Seasonal dynamics of $\mathrm{N}_{2}$ fixation at the two long-term observational stations BATS (Bermuda Atlantic Time Series Study) and ALOHA (A Long-term Oligotrophic Habitat Assessment) are roughly captured. For a detailed description and model evaluation see Paulsen et al. (2017).

The simulated annual mean distribution of chlorophyll (Fig. 1c), derived from bulk phytoplankton and cyanobacteria (PHY_CYA), qualitatively reproduces the main global patterns of chlorophyll $a$ estimates deduced from satellite measurements of ocean color (e.g., SeaWiFS Project, 2003; 
(a)

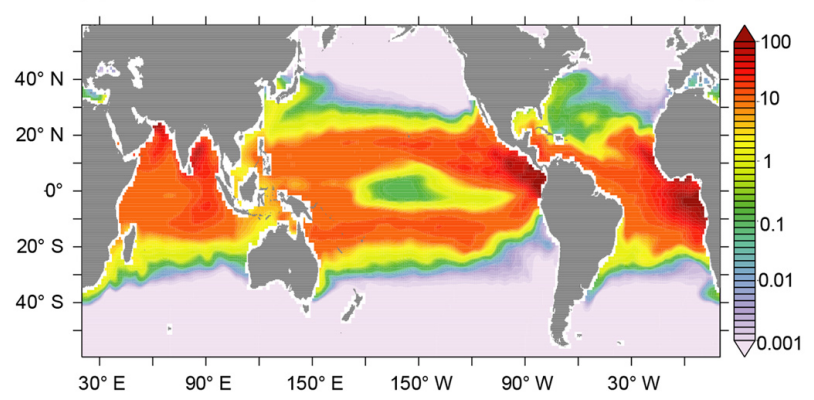

(b)

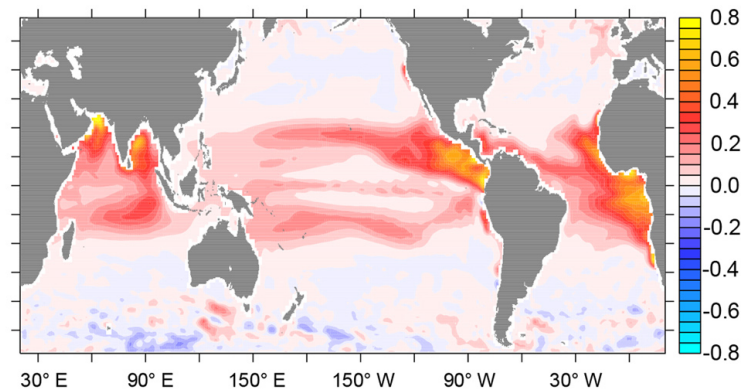

(c)

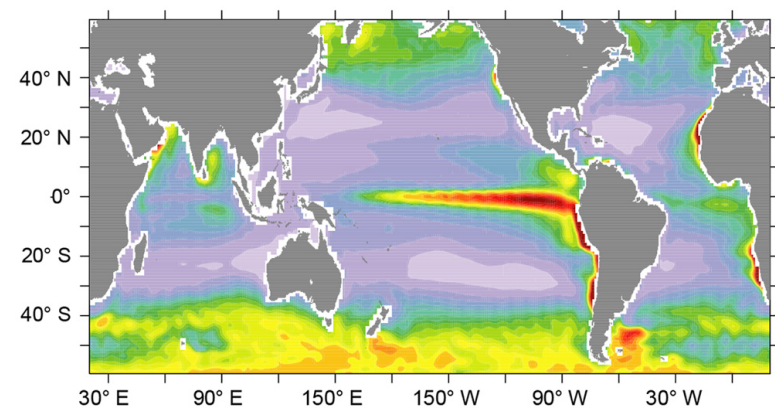

(d)

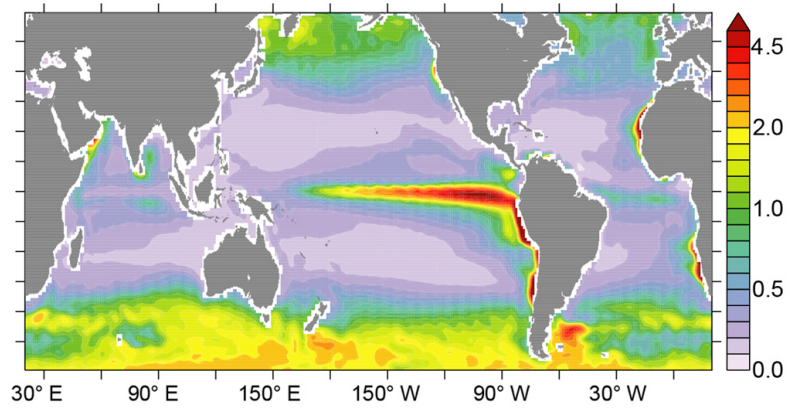

Figure 1. (a) Climatological annual mean cyanobacteria concentrations $\left(\mathrm{mg} \mathrm{C} \mathrm{m}^{-3}\right)$ in the upper $22 \mathrm{~m}$ in PHY_CYA. Note the nonlinear color scale. (b) Difference in the climatological annual mean chlorophyll $\left(\mathrm{mg} \mathrm{Chl} \mathrm{m}^{-3}\right)$ in the upper $22 \mathrm{~m}$ between PHY_CYA and PHY_ONLY. (c) Climatological annual mean global chlorophyll concentrations $\left(\mathrm{mg} \mathrm{Chl} \mathrm{m}^{-3}\right)$ in the upper $22 \mathrm{~m}$ as used for the light attenuation scheme in the physical model in PHY_CYA, and (d) in PHY_ONLY.

Gregg et al., 2005). For the presented comparison, it is assumed that the general large-scale patterns and the order of magnitude of the concentrations have not considerably changed between the preindustrial and the satellite era. High simulated values of chlorophyll occur in high latitudes north and south of $40^{\circ}$ latitude (annual mean approx. 0.5$3 \mathrm{mg} \mathrm{Chl} \mathrm{m}^{-3}$ ) as well as in the nutrient-rich upwelling regions at the Equator and along the eastern boundaries of the ocean basins (annual mean approx. $1-5 \mathrm{mg} \mathrm{Chl} \mathrm{m}^{-3}$ ). In the equatorial Pacific, chlorophyll values are overestimated by the model, due to too high biological production caused by too strong upwelling (Ilyina et al., 2013). Low chlorophyll values, on the other hand, are present in the oligotrophic areas of the downwelling regions in the central subtropical gyres (annual mean approx. $0.1-0.3 \mathrm{mg} \mathrm{Chl} \mathrm{m}^{-3}$ ). The simulated values in these regions are slightly higher than satellite estimates of chlorophyll $\left(0.03-0.2 \mathrm{mg} \mathrm{Chl} \mathrm{m}^{-3}\right.$, e.g., Gregg et al., 2005).

The contribution of cyanobacteria to annual mean surface chlorophyll becomes visible in the comparison between experiment PHY_CYA (Fig. 1c) and PHY_ONLY (Fig. 1d) shown in Fig. 1b, where in PHY_ONLY cyanobacteria are made transparent with respect to shortwave radiation. In the tropical and subtropical ocean, the contribution of cyanobacteria to surface chlorophyll is in the order of $0.1-$
$0.3 \mathrm{mg} \mathrm{Chl} \mathrm{m}^{-3}$, regionally up to $0.8 \mathrm{mg} \mathrm{Chl} \mathrm{m}^{-3}$. This represents up to $80 \%$ of the total surface chlorophyll concentrations in certain regions (e.g., in the eastern equatorial Atlantic and Pacific). The large contribution of cyanobacteria to surface chlorophyll in certain regions can be explained; first, by their capability to grow in nitrate-depleted areas (in contrast to bulk phytoplankton); and second, by the fact that they are concentrated at the surface due to their positive buoyancy (in contrast to neutrally buoyant bulk phytoplankton, which show a deep chlorophyll maximum at roughly $50-100 \mathrm{~m}$ in large parts of the tropical and subtropical ocean in summer months). In bloom conditions, cyanobacteria biomass is often confined to the upper first meter in the real ocean. In the model, the first layer is, however, $12 \mathrm{~m}$ thick. If the simulated chlorophyll content of cyanobacteria of the first model layer with an annual mean concentration of up to $0.9 \mathrm{mg} \mathrm{Chl} \mathrm{m}^{-3}$ was confined more to the surface (e.g., to the upper first meter) this would convert to a value of $10.8 \mathrm{mg} \mathrm{Chl} \mathrm{m}^{-3}$, which lies within the range of reported values for Trichodesmium blooms (approx. 0.8$40 \mathrm{mg} \mathrm{Chl} \mathrm{m}^{-3}$; e.g., Subramaniam et al., 2001; Westberry and Siegel, 2006; Mohanty et al., 2010). Overall, the simulated values of cyanobacteria chlorophyll concentrations are thus of a plausible order of magnitude. 
In experiment PHY_CYAx2, the patterns of cyanobacteria and chlorophyll are consistent with PHY_CYA (not shown). The chlorophyll values are, however, roughly doubled. Mean cyanobacteria chlorophyll values reach $1.6 \mathrm{mg} \mathrm{Chl} \mathrm{m}^{-3}$. Blooms would have a chlorophyll concentration of $21.6 \mathrm{mg} \mathrm{Chl} \mathrm{m}^{-3}$ if confined to the first meter, which also lies within the reported range.

\section{Effects of cyanobacteria light absorption on the mean tropical climate state}

\subsection{Effects on ocean temperature and MLD}

Including light absorption by cyanobacteria in addition to bulk phytoplankton (experiment PHY_CYA compared to PHY_ONLY) has a warming effect on SST in some limited areas of the tropical ocean (Fig. 2a). In contrast, a cooling effect on SST dominates larger areas. The mean cooling effect in the tropical area $\left(20^{\circ} \mathrm{S}-20^{\circ} \mathrm{N}\right)$ is small $(0.07 \mathrm{~K})$. Regionally, however, the negative SST anomalies reach values of up to $0.5 \mathrm{~K}$ in PHY_CYA, which is significantly larger than the internal variability of the model (dotted areas in Fig. 2b indicate statistically significant anomalies at the $90 \%$ confidence level according to the student's $t$ test). The strongest negative anomalies occur at the Equator and in the eastern boundary upwelling systems off the South American and African continents. The surface cooling can be explained by the following mechanism. The presence of cyanobacteria increases light absorption in the upper layers. Radiative heating is thus more confined to the surface, causing a significant shoaling of the MLD by up to $10 \mathrm{~m}$ (Fig. 2d) and a shoaling of the thermocline depth (shown for the equatorial Pacific in Fig. 3). At the same time, deeper layers receive less radiation, which leads to a decrease in subsurface temperature (Fig. 2c), in the global zonal mean by up to $0.5 \mathrm{~K}$ (Fig. 4). The cold signal reaches below the MLD and down to the thermocline (defined here as the depth of the $20^{\circ} \mathrm{C}$ isotherm). This subsurface water feeds the shallow overturning cells and is transported equatorward along the thermocline (which is equivalent with the pycnocline in the tropics). At the Equator, the relatively cooler subsurface water is upwelled, where it outweighs the direct heating effect due to local cyanobacteria light absorption at the surface. The upwelled water is spread laterally via the poleward surface Ekman transport and leads to a cooling in large parts of the tropical and subtropical ocean. Hence, instead of the expected surface heating induced by the presence of cyanobacteria, the advective process bringing relatively cooler subsurface water to the surface dominates. In addition, the atmospheric cooling above respective regions spreads throughout the troposphere and enhances the surface cooling in other regions due to an enhanced heat flux directed from the ocean into the atmosphere (not shown).

The cold upwelled subsurface water originates from regions where cyanobacteria are abundant and shade the deeper (a) $\quad \Delta S S T$ (PHY_CYA - PHY_ONLY)

[K]

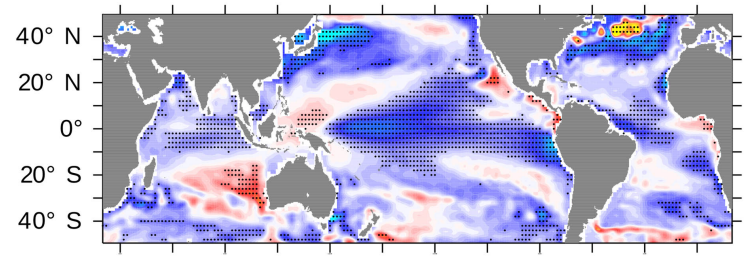

(b) $\quad \Delta S S T$ (PHY_CYAX2 - PHY_ONLY)

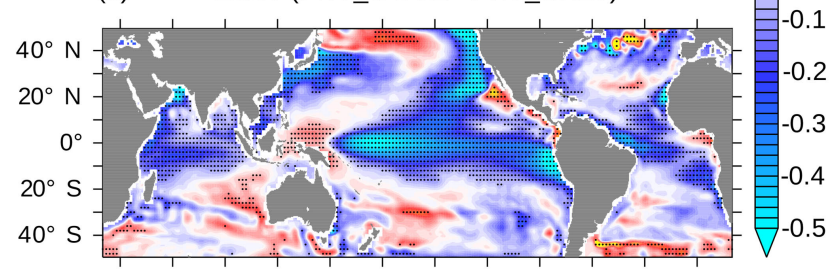

(c) $\quad \Delta \mathrm{T} 100 \mathrm{~m}\left(\mathrm{PHY} \_\mathrm{CYA}-\mathrm{PHY}\right.$ _ONLY)

[K]

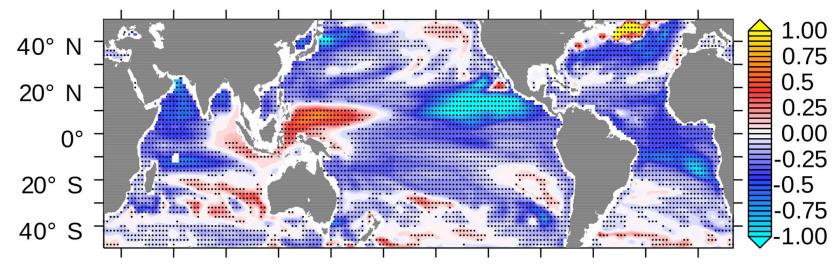

(d) $\quad \triangle M L D\left(P H Y \_C Y A-P H Y \_O N L Y\right)$

[m]

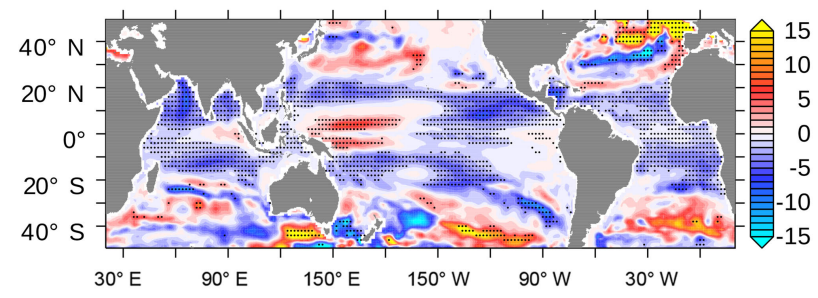

Figure 2. (a) Difference in the climatological annual mean SST (K) between PHY_CYA and PHY_ONLY and (b) between PHY_CYAx2 and PHY_ONLY. (c) Difference in the climatological annual mean temperature at a depth of $100 \mathrm{~m}(\mathrm{~K})$, and (d) MLD (m) between PHY_CYA and PHY_ONLY. Dotted areas indicate statistically significant anomalies at the $90 \%$ confidence level (student's $t$ test).

layers (Fig. 1a and b). These regions mainly comprise two different physical regimes. The first regime includes the downwelling regions of the subtropical gyres in which the cooler water is subducted within the shallow meridional overturning cells and then transported equatorward along the thermocline. The second regime includes the eastern boundary upwelling regions at the margins of the subtropical gyres (the eastern tropical Atlantic north and south of the Equator, and the eastern tropical Pacific north of the Equator). Here, overall high cyanobacteria concentrations are present, which strongly shade and hence cool the subsurface layers. Also from here, the water partly ends up in the shallow meridional 


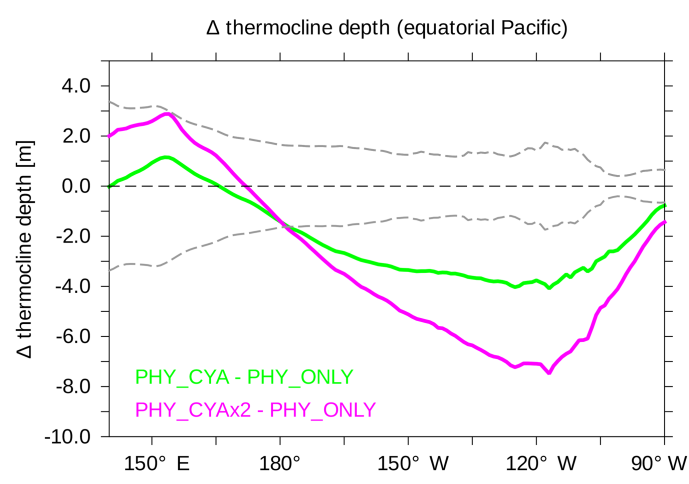

Figure 3. Difference in the climatological mean thermocline depth (m) between PHY_CYA and PHY_ONLY (green) and PHY_CYAx2 and PHY_ONLY (purple). To provide a sense for the internal variability in the model, the grey dashed lines show \pm 2 times the standard deviation of eight 100 -year periods of CTRL.

overturning cells and the equatorial upwelling system, contributing to the cold SST signal seen at the Equator. Due to the complexity of the circulation system and the exchange pathways between the tropical and subtropical ocean, it is difficult to distinguish contributions of the subtropical gyres from contributions of their margins.

Besides the SST decrease, which dominates large parts of the tropical and subtropical ocean in PHY_CYA compared to PHY_ONLY, there are some limited regions with a significant annual mean SST increase (Fig. 2a). These regions include the eastern equatorial Atlantic and the eastern equatorial Pacific adjacent to the coast. In these regions, the direct heating by high cyanobacteria concentrations together with the decrease in upwelling strength (as will be discussed in Sect. 4.3), outweighs the upwelling effect of cooler subsurface water and results in a surface warming. Whether light absorption by cyanobacteria locally leads to a mean surface warming or cooling thus depends on two opposing effects: the local heating due to light absorption and the non-local cooling due to upwelling of cooler subsurface water. Which process dominates, strongly depends on the region and on the local cyanobacteria concentrations. Two other regions with significant positive SST anomalies are the western Pacific warm pool and the eastern subtropical Indian Ocean. In these regions, it is not the local effect of high light absorption causing anomalies, but changes in the circulation (Sect. 4.3).

In the sensitivity experiment, PHY_CYAx2, the patterns of change in SST relative to PHY_ONLY are consistent with PHY_CYA relative to PHY_ONLY (compare Fig. 2a and b, respectively). The magnitudes of the anomalies, both the positive and negative ones, are enlarged by roughly a factor of 2 (e.g., equatorial Pacific: approx. 0.6 K in PHY_CYAx2 compared to approx. $0.3 \mathrm{~K}$ in PHY_CYA). The higher chlorophyll content of cyanobacteria leads to a stronger local warming in regions where they are present. But at the same time this also leads to a stronger shading of the subsurface wa-

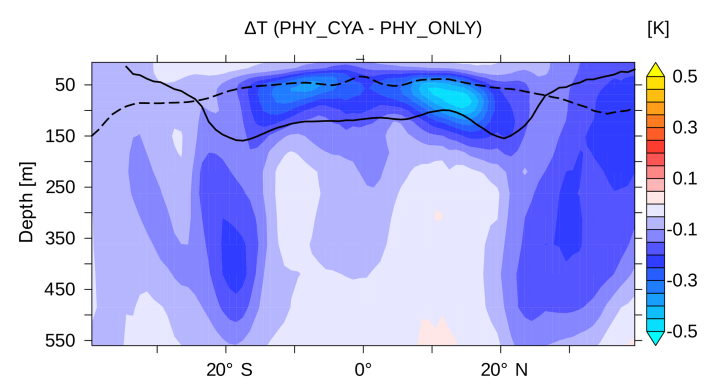

Figure 4. Difference in the climatological global zonal mean temperature $(\mathrm{K})$ in the upper $550 \mathrm{~m}$ between PHY_CYA and PHY_ONLY. The dashed black line shows the global zonal mean MLD and the solid black line the global zonal mean thermocline depth (defined as the depth of the $20^{\circ} \mathrm{C}$ isotherm) in PHY_ONLY.

ter, which enhances the subsurface cooling and brings cooler water to the surface. The resulting patterns of the net effect (cooling or warming) are consistent between the two experiments. The consistency of the anomaly patterns between PHY_CYAx2 and PHY_CYA (relative to PHY_ONLY) also counts for most other quantities that are analyzed in this study. Thus, in the following, only the anomaly maps for experiment PHY_CYA are shown. The respective numbers for PHY_CYAx2 are stated in the text.

\subsection{Effects on wind patterns and precipitation}

The cooling of the cold tongue in the east Pacific and heating of the warm pool in the west Pacific in experiment PHY_CYA compared to PHY_ONLY intensifies the zonal SST gradient, implying a strengthening of the Walker circulation above the western Pacific warm pool (Fig. 5c). The ascent of the air over the warm pool is enhanced west of $150^{\circ} \mathrm{E}$ by roughly $6 \%$ ( $13 \%$ in PHY_CYAx 2 ) (vertical velocity $\omega$ at $500 \mathrm{hPa}$ averaged from 120 to $140^{\circ} \mathrm{E}$ ). Related to this, the equatorial easterly winds are intensified west of $160^{\circ} \mathrm{W}$ (Fig. 5a and b), enhancing the westward wind stress on the ocean (not shown). Furthermore, the transition between the convection and the subsidence zone of the Walker circulation is shifted westward by approx. $3^{\circ}$ longitude (approx. $6^{\circ}$ longitude in PHY_CYAx2; Fig. 5c). This is a significant change, larger than the internal variability in the model, which is estimated as \pm 2 times the standard deviation of eight 100-year periods of experiment CTRL (dashed grey lines in Fig. 5c). In other words, the convection gets stronger, but more confined to the western part of the Pacific basin.

The strong cold SST anomaly at the Equator generally reduces the meridional SST gradient between the equatorial zone and the extratropics (Fig. 2a). This results in weaker trade winds and a weakening of the Hadley circulation (Fig. 5a and b). At the same time, the Hadley cells are slightly expanded polewards, which leads to a slight northward shift of the western boundary currents (Kuroshio Current and Gulf Stream) as visible in the dipole SST pattern (Fig. 2a). 

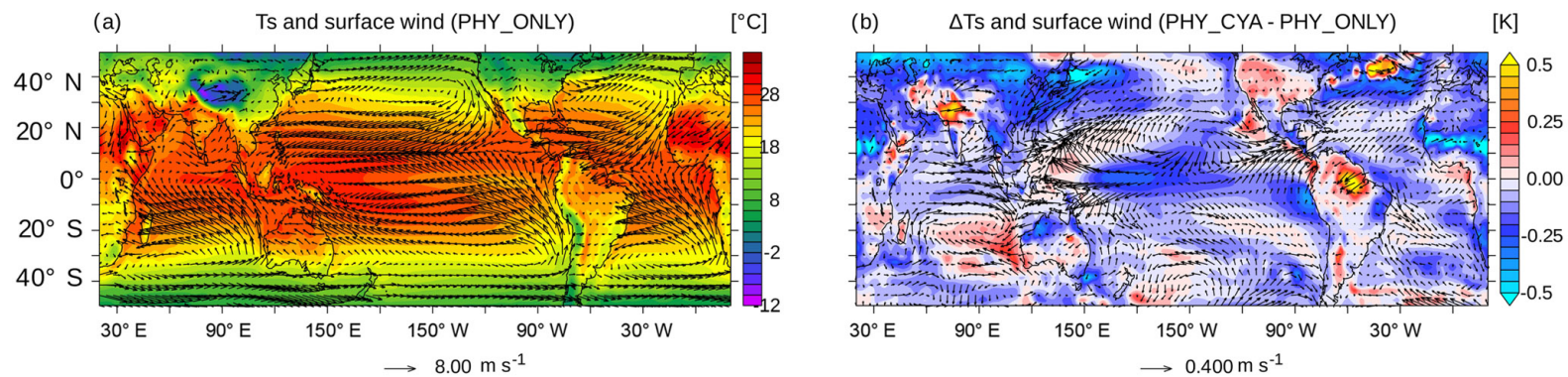

(c)

$\omega$ at $500 \mathrm{hPa}$ (equatorial Pacific)

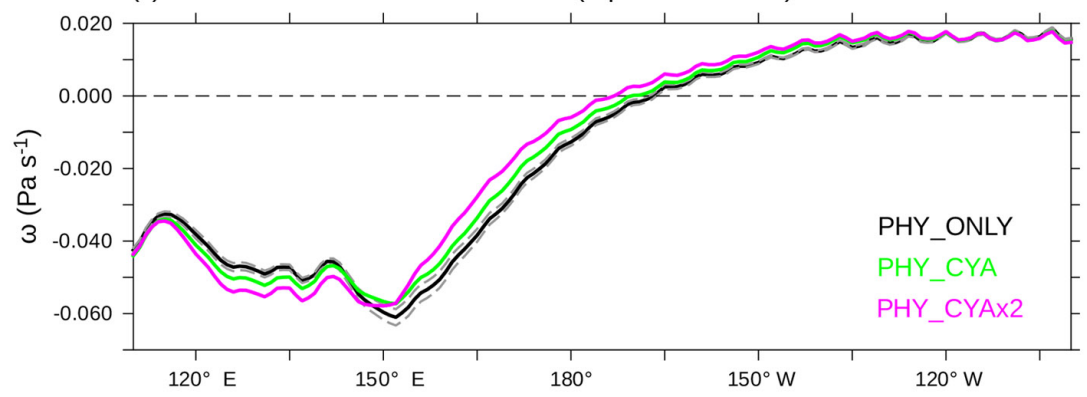

(d)

Precip (PHY_ONLY)

$\left[\mathrm{mm} \mathrm{d}^{-1}\right]$

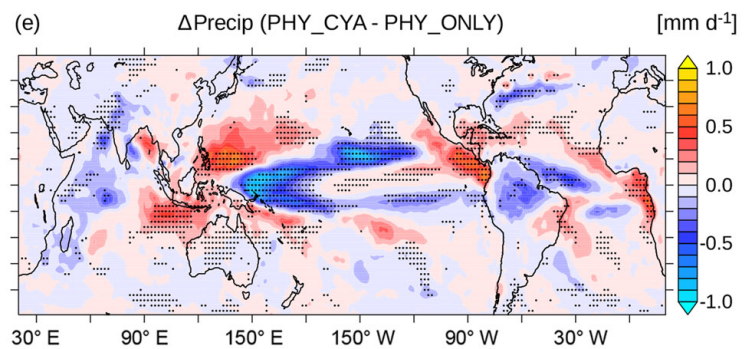

Figure 5. (a) Climatological mean surface air temperatures $\left({ }^{\circ} \mathrm{C}\right)$ and vectors of surface winds $\left(\mathrm{m} \mathrm{s}^{-1}\right)$ in PHY_CYA. (b) Difference in the climatological annual mean surface air temperature $(\mathrm{K})$ and vectors of surface wind anomalies $\left(\mathrm{m} \mathrm{s}^{-1}\right)$ between PHY_CYA and PHY_ONLY. (c) Climatological mean vertical velocity $\omega\left(\mathrm{Pa} \mathrm{s}^{-1}\right)$ at $500 \mathrm{hPa}$ above the equatorial Pacific $\left(10^{\circ} \mathrm{S}-10^{\circ} \mathrm{N}\right)$ in PHY_ONLY (black, \pm 2 times the standard deviation of eight 100-year periods of CTRL in dashed grey), PHY_CYA (green) and PHY_CYAx2 (purple). (d) Climatological annual mean precipitation $\left(\mathrm{mm} \mathrm{day}^{-1}\right.$ ) in PHY_CYA. (e) Difference in the climatological annual mean precipitation (mm day ${ }^{-1}$ ) between PHY_CYA and PHY_ONLY. The dotted areas indicate statistically significant anomalies at the $90 \%$ confidence level (student's $t$ test).

The strongest effect on precipitation can be seen over the western equatorial Pacific (Fig. 5e). There, the strong decrease in equatorial SST at $160^{\circ} \mathrm{E}$ (Fig. 2a) and the zonal displacement of the Walker circulation (Fig. 5c) lead to a change in the location and strength of convection and precipitation. Precipitation significantly decreases with a maximum centered at approx. $160^{\circ} \mathrm{E}$ by up to $1.0 \mathrm{~mm} \mathrm{day}^{-1}$ (up to $1.6 \mathrm{~mm} \mathrm{day}^{-1}$ in PHY_CYAx2), and extending off-Equator in latitudinal bands at about $10^{\circ} \mathrm{S}$ and $10^{\circ} \mathrm{N}$ towards the east. A significant decrease is also seen above the cold SST anomalies in the western Indian Ocean, as well as the western tropical Atlantic and over the Amazon region. In the eastern parts of the ocean basins - the eastern equatorial Atlantic, Pacific, and Indian Ocean - relatively warmer surface water, on the other hand, increases convection and hence precipita- tion by up to approx. $0.8 \mathrm{~mm} \mathrm{day}^{-1}$ (approx. $1.0 \mathrm{~mm} \mathrm{day}^{-1}$ in PHY_CYAx2).

\subsection{Effects on ocean circulation}

The weakening of the Hadley cells in PHY_CYA (and PHY_CYAx2) compared to PHY_ONLY implies a weakening of the wind-driven ocean circulation. The barotropic stream function $\Psi$, which describes the large-scale horizontal ocean circulation, significantly decreases in magnitude both in the subtropical as well as in the equatorial gyres (Fig. 6a and b). The dipole anomaly patterns within the subtropical gyres in the Northern Hemisphere indicate a poleward shift of its boundaries. This feature is most dominant in the North Atlantic, where the weakening in the southern part and 
(a)

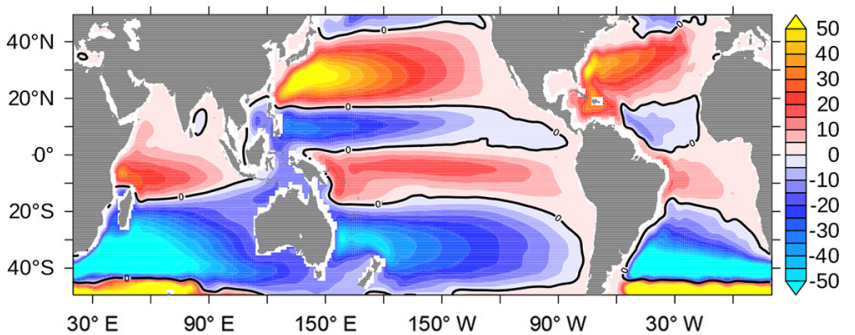

(c)

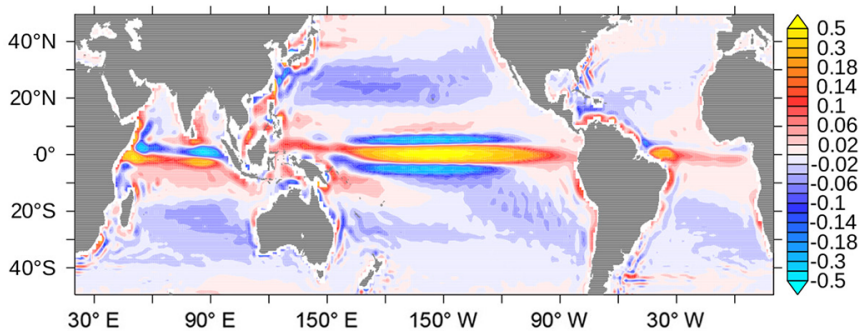

(b) $\triangle \Psi$ (PHY_CYA - PHY_ONLY)

[Sv]

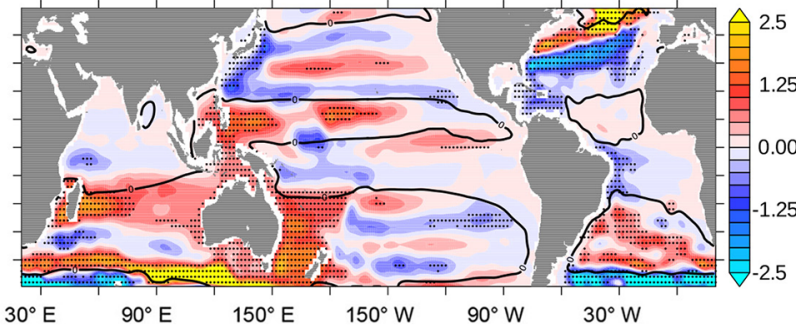

(d)

$\Delta$ Vert. transport (PHY_CYA - PHY_ONLY)

[Sv]

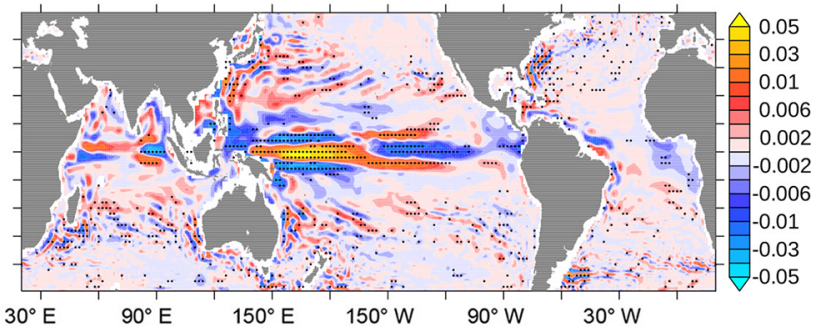

Figure 6. (a) Climatological mean barotropic stream function $\Psi$ (Sv, sverdrup) in PHY_ONLY. The zero isoline is overlaid in black. (b) Difference in the climatological mean $\Psi$ (Sv) between PHY_CYA and PHY_ONLY. The zero isoline of PHY_ONLY is overlaid in black. (c) Climatological mean vertical transport in the upper $100 \mathrm{~m}(\mathrm{~Sv})$ in PHY_ONLY. Note the nonlinear color scaling with $0.01 \mathrm{~Sv}$ between -0.2 and $0.2 \mathrm{~Sv}$ and $0.1 \mathrm{~Sv}$ for the remaining range. (d) Difference in the climatological annual mean vertical transport in the upper $100 \mathrm{~m}$ (Sv) between PHY_CYA and PHY_ONLY. Note the non-linear color scaling with 0.001 Sv between -0.01 and 0.01 Sv and 0.01 Sv for the remaining range. The dotted areas in (b) and (d) indicate statistically significant anomalies at the $90 \%$ confidence level (student's $t$ test).

strengthening in the northern part reflect a northward shift of the position of the Gulf Stream and the North Atlantic Current, respectively. The northward shift is also visible in the strong negative temperature anomaly that is present at the surface (Fig. 2a) and reaches down to greater depth (Fig. 4).

In the tropical Pacific north of the Equator, the increase in annual mean southward wind stress along the Southeast Asian coast $\left(10-30^{\circ} \mathrm{N}\right.$, approx. $120^{\circ} \mathrm{E}$; Fig. 5a and b) reduces the northward warm water transport of the Kuroshio Current. This, together with the slight northward shift of the Kuroshio Current, leads to the strong negative SST anomaly, which reaches into the interior of the ocean basin (Fig. 2a).

In the Indian Ocean, both the equatorial and the subtropical gyres are generally weaker in PHY_CYA compared to PHY_ONLY and the boundary between them is slightly shifted southwards (Fig. 6a and b). The significant reduction in strength of the Indian Ocean subtropical gyre is accompanied by a weakening of the so-called Southern Hemisphere "supergyre" (e.g., Speich et al., 2007), which extends into the South Atlantic. The associated reduced transport of warm water from the Indian Ocean into the South Atlantic ocean is visible in the cold SST signal around the tip of South Africa (Fig. 2a). This cooling effect enhances the negative SST signal that occurs at the eastern margin of the South Atlantic due to the upwelling of colder subsurface water in the Benguela Upwelling System.
In the Atlantic Ocean, the reduction of the trade winds (Fig. 5a and b) and the related wind stress on the ocean (not shown) reduces equatorial divergence. The related weakening of the overturning cells slightly damps equatorial upwelling and reduces downwelling in the subtropical gyres (Fig. 6c). Thus, the atmospheric response to the SST anomaly pattern does not amplify the negative equatorial SST signal, but rather damps it, by causing less transport of cold subsurface water to the surface. In combination with the local heating due to high cyanobacteria concentrations, this results in a positive SST signal at the eastern boundary (Fig. 2a). In the Pacific Ocean, a similar behavior of weaker trade winds and weaker equatorial upwelling (Fig. 6d) can be seen in the eastern part of the basin (east of $160^{\circ} \mathrm{W}$ ). In the western part, on the contrary, the strengthening of the westward surface current related to the change in the Walker circulation increases equatorial upwelling. Here, the atmospheric feedback intensifies the surface cooling effect. This explains the larger SST signal in the western central Pacific Ocean compared to the east (Fig. 2a). In summary, the atmospheric feedback amplifies the SST signal in the western Pacific by enhancing the upwelling strength, and damps it in the eastern Pacific and the Atlantic Ocean by reducing the upwelling strength. 
(a)

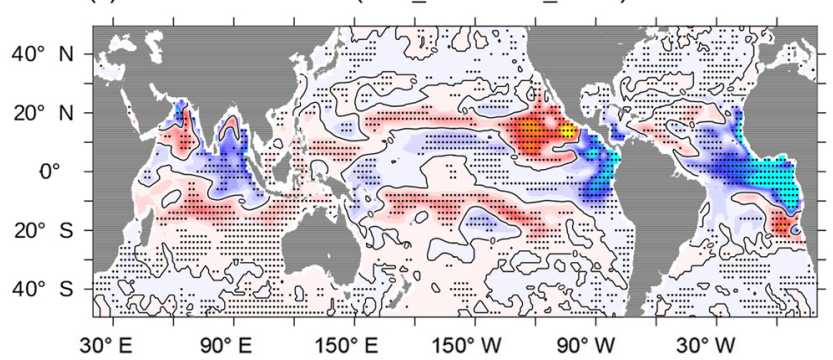

(b)

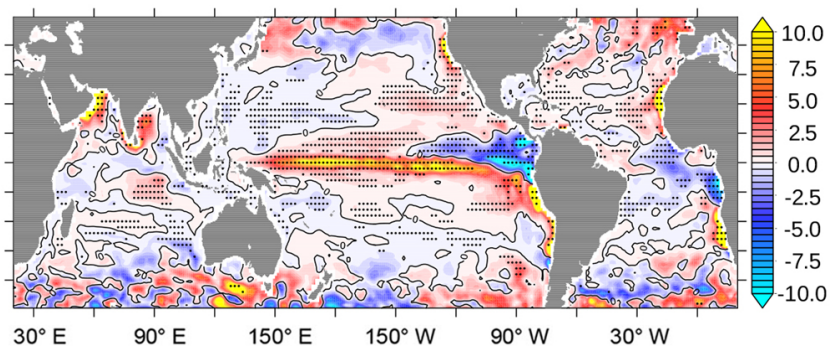

Figure 7. Change in (a) climatological annual mean surface (0-22 m) cyanobacteria concentrations ( $\mathrm{mg} \mathrm{C}^{-3}$ ) and (b) surface bulk phytoplankton concentrations ( $\mathrm{mg} \mathrm{C} \mathrm{m}^{-3}$ ) between PHY_CYA and PHY_ONLY. The zero isolines are overlaid in black. The dotted areas indicate statistically significant anomalies at the $90 \%$ confidence level (student's $t$ test).

\subsection{Feedback on phytoplankton abundance}

By comparing the simulations with and without cyanobacteria light absorption we quantify how cyanobacteria-induced changes in the physical ocean state feed back on the growth conditions of cyanobacteria and bulk phytoplankton itself. Globally integrated, the biogeochemical mean states in PHY_CYA, PHY_CYAx2, and PHY_ONLY do not differ notably from each other in quantities like the total cyanobacteria and phytoplankton biomass, nitrogen fixation, and primary production. Regionally, however, significant changes in the concentrations of bulk phytoplankton and cyanobacteria occur (Fig. 7). Thereby, phytoplankton concentrations, both of cyanobacteria and bulk phytoplankton, do not uniformly decrease or increase, but show a more complex pattern of change. Hence, we cannot generally refer to a positive or negative feedback between ocean physics and cyanobacteria light absorption. A positive feedback means that induced changes in ocean circulation and temperature result in an increase in cyanobacteria biomass, which further enhances the initial perturbation - i.e., the increase in light absorption strength. This is indeed the case in the subtropical bands of the Pacific Ocean. Here, the cyanobacteria abundance results in cooling of equatorial SST (Fig. 2a), which shifts the Walker circulation westward (Fig. 5c), implying an increase in upwelling strength in the western equatorial Pacific (Fig. 6d). The related increased abundance of nutrients at the surface is spread poleward via Ekman transport and promotes growth of cyanobacteria (and partially also bulk phytoplankton) in the subtropical bands at about approx. $10-20^{\circ} \mathrm{S}$ and approx. 10-20 $\mathrm{N}$ (Fig. 7), closing the positive feedback loop. In the eastern tropical Atlantic and Indian Ocean, as well as the eastern equatorial Pacific, the decrease in upwelling strength and the increase in SST above the optimum temperature of $28^{\circ} \mathrm{C}$ impair cyanobacteria growth conditions and results in a strong decline in cyanobacteria concentrations of up to $25 \%$ (Fig. 7a). In experiment PHY_CYAx2, the decline in these regions reaches values of up to $60 \%$ (not shown). The cyanobacteria decline damps the effect of light absorption, thus constituting a negative feedback. The strong increase in bulk phytoplankton in the equatorial Pacific, as well as in the eastern boundary upwelling areas (Fig. 7b), also damps the cooling effect due to the large increase in surface light absorption directly at the upwelling sites. In summary, the net effect of including the effect of light absorption by cyanobacteria on cyanobacteria and phytoplankton growth is regionally variable and results from an interplay of different physical and biogeochemical processes.

\section{Effects of cyanobacteria light absorption on seasonal dynamics and interannual variability in SST}

Including cyanobacteria light absorption modifies not only the mean climate state but also the seasonal SST amplitude as well as interannual SST variability. We find an increase in the amplitude of the climatological mean seasonal cycle of SST in PHY_CYA compared to PHY_ONLY in large parts of the tropical and subtropical ocean, regionally by up to approx. $25 \%$ (Fig. 8; in PHY_CYAx2 up to approx. 50\%). In large parts, this increase improves the model performance in comparison to the observed amplitude of the seasonal cycle (Reynolds et al., 2007, not shown). The increase in the simulated amplitude is characterized by either an increase in the maximum annual monthly mean temperature (caused by the direct heating of local cyanobacteria biomass) or by a decrease in the minimum annual monthly mean temperature (caused by the indirect cooling due to the upwelling of subsurface water and its subsequent lateral transport), or by a combination of both. Both processes have their own - partly interdependent - seasonal dynamics. The changes in temperature and upwelling strength furthermore feed back on the cyanobacteria abundance. We select two locations (the western and eastern tropical Atlantic) and show the climatological seasonal cycle of SST and surface cyanobacteria biomass (Fig. 8b, black boxes) to illustrate that, depending on the region, different factors play a role.

In the western Atlantic equatorial upwelling region, a stronger surface cooling prevails all year round in PHY_CYA (and PHY_CYAx2) compared to PHY_ONLY (Fig. 9a) due 
(a)

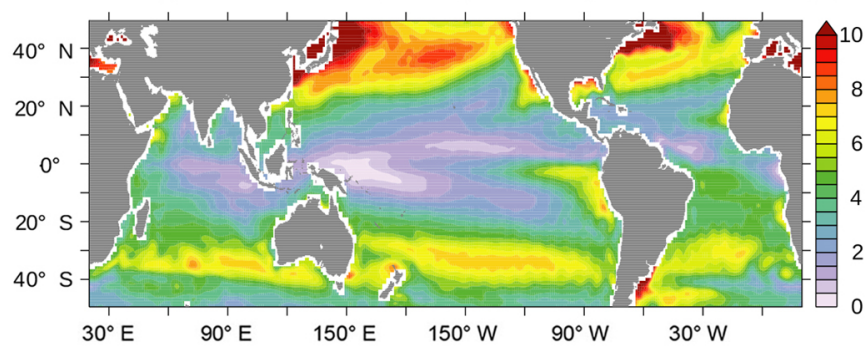

(b) $\triangle$ SST amplitude (PHY CYA - PHY ONLY)

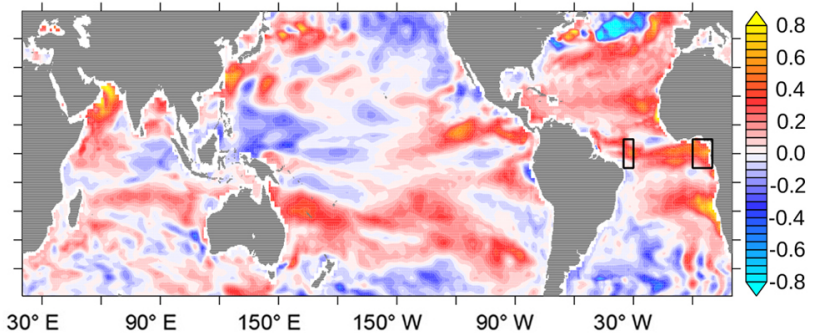

Figure 8. (a) Climatological mean amplitude of the seasonal cycle of SST (K) in PHY_ONLY. (b) Difference in the climatological mean amplitude of the seasonal cycle of SST (K) between PHY_CYA and PHY_ONLY. The black boxes display the locations discussed in Sect. 5 (Fig. 9).

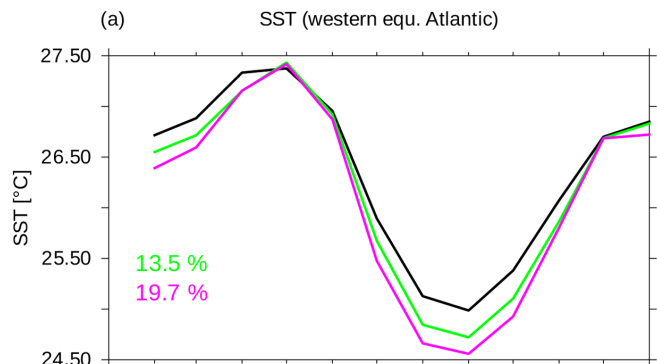

(c)

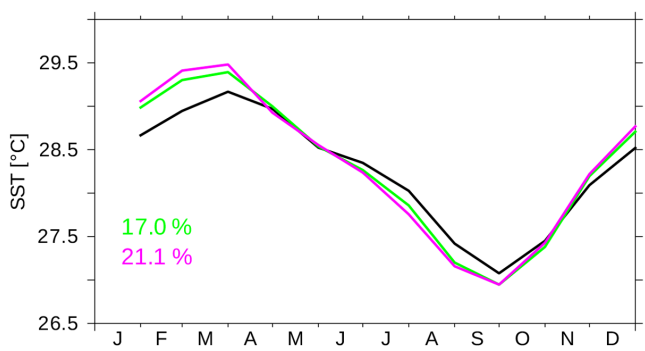

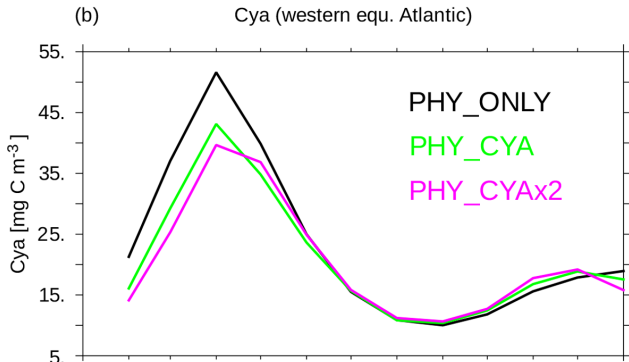

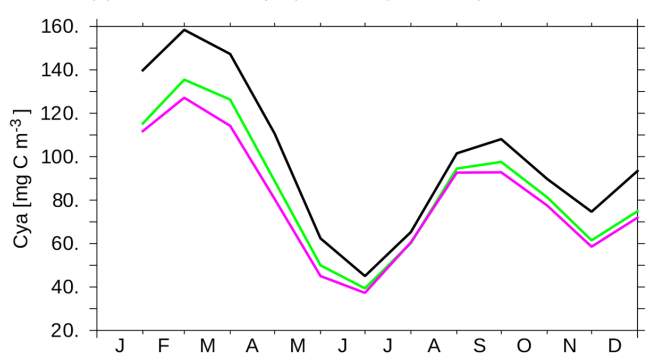

Figure 9. (a, c) Climatological monthly mean seasonal cycle of SST $\left({ }^{\circ} \mathrm{C}\right)$ in the western (a, b) and eastern (c, d) tropical Atlantic in PHY_ONLY (black), PHY_CYA (green), and PHY_CYAx2 (purple). The displayed numbers show the change in the amplitude in percentage. (b, d) Climatological mean seasonal cycle of surface cyanobacteria concentrations $\left(\mathrm{mg} \mathrm{C} \mathrm{m}^{-3}\right)$ in the western $(\mathbf{a}, \mathbf{b})$ and eastern $(\mathbf{c}, \mathbf{d})$ tropical Atlantic in PHY_ONLY (black), PHY_CYA (green), and PHY_CYAx2 (purple). The locations are shown as black boxes in Fig. 8b.

to upwelling of relatively cooler subsurface water. The decrease is stronger from July to September (due to low cyanobacteria concentrations and hence surface light absorption), resulting in an increased amplitude of the seasonal cycle of $13.5 \%$ in PHY_CYA (19.7\% in PHY_CYAx2), which slightly impairs the model results in comparison to the observed amplitude of the seasonal cycle at this location (Reynolds et al., 2007). Cyanobacteria concentrations are lower in PHY_CYA (and PHY_CYAx2) compared to PHY_ONLY at the beginning of the year due to weaker upwelling (Fig. 9b).

In the eastern equatorial Atlantic (Gulf of Guinea), maximum temperatures between December and March are increased in PHY_CYA (and PHY_CYAx2) compared to PHY_ONLY due to the surface heating effect of the high local cyanobacteria concentrations, which prevail in this period. From May to October, on the other hand, the cyanobacteria concentrations - and hence the surface warming effect - decrease and, instead, the upwelling of colder subsurface water dominates and results in a slight decrease in SST. In total, the amplitude of the seasonal cycle of SST is enhanced (17.0\% in PHY_CYA, $21.1 \%$ in PHY_CYAx2, Fig. 9c). This brings it slightly closer to the observed amplitude (Reynolds et al., 2007, not shown), which is generally underestimated in the model in this region of the ocean. Cyanobacteria growth and concentrations are reduced in PHY_CYA (and PHY_CYAx2) compared to PHY_ONLY all year round (Fig. 9d) since the upwelling strength is weaker (Fig. 6d) and SST exceeds the optimum value of $28^{\circ} \mathrm{C}$ in the beginning of the year. 

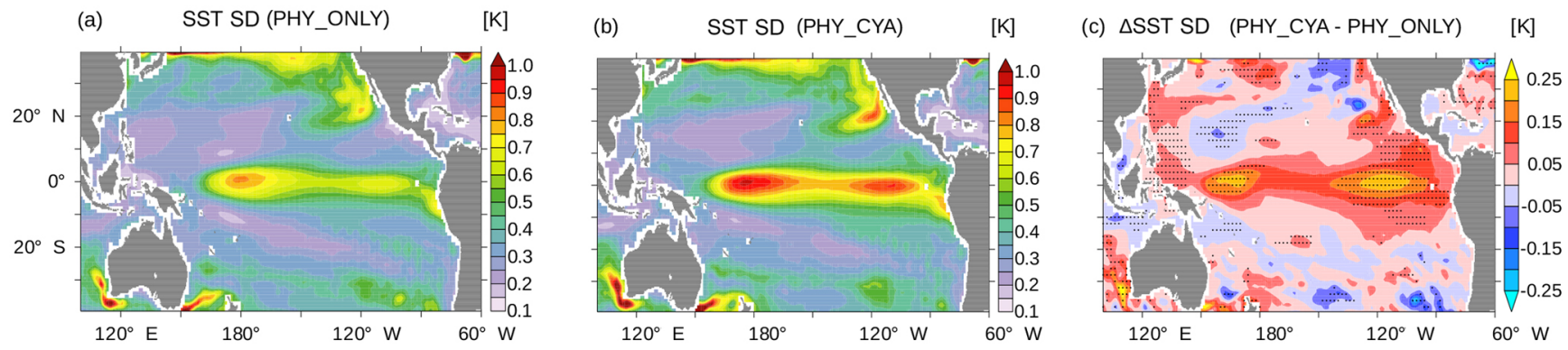

Figure 10. Standard deviation (SD) of SST (K) in the tropical Pacific in (a) PHY_ONLY and (b) PHY_CYA, and (c) the difference between PHY_CYA and PHY_ONLY. The dotted areas show anomalies larger than \pm 2 times the standard deviation of eight 100 -year periods of CTRL.

Besides the seasonal dynamics of SST, the interannual variability in SST is also affected by cyanobacteria light absorption. The interannual standard deviation of SST in the equatorial Pacific $\left(10^{\circ} \mathrm{S}-10^{\circ} \mathrm{N}, 160^{\circ} \mathrm{E}-80^{\circ} \mathrm{W}\right)$ is increased by $21.8 \%$ in PHY_CYA compared to PHY_ONLY (Fig. 10a and $b$ ), which exceeds an estimate of centennial anomalies of the model (Fig. 10c, dots show significant anomalies larger than \pm 2 times the standard deviation of eight 100 -year periods of CTRL). Regionally, the increase reaches values of $60 \%$. The Niño 3.4 index (SST anomalies averaged over the area $5^{\circ} \mathrm{S}-5^{\circ} \mathrm{N}, 170-120^{\circ} \mathrm{W}$ ) is increased by $16 \%$ (from $0.69 \mathrm{~K}$ in PHY_ONLY to $0.80 \mathrm{~K}$ in PHY_CYA). The increase in variability is probably related to the mean state changes induced by the presence of cyanobacteria: first, the increased asymmetry in zonal SST due to the cooling of the cold tongue (Fig. 2a); and second, the shoaling of the equatorial thermocline (Fig. 3). Both factors are generally proposed to increase variability in tropical SST and El Niño Southern Oscillation (ENSO) (e.g., Collins et al., 2010; Meehl et al., 2001). Hence, cyanobacteria, although mainly growing offEquator, influence ENSO dynamics by remotely modifying SST and the thermocline depth at the Equator.

Also, in experiment PHY_CYAx2, interannual variability is increased compared to PHY_ONLY (not shown). Interestingly, a stronger cooling of the cold tongue (Fig. 2b) and shoaling of the equatorial thermocline (Fig. 3) in PHY_CYAx2 compared to PHY_CYA does not lead to a stronger increase in variability (e.g., Collins et al., 2010; Meehl et al., 2001). The increase is slightly lower (17.1\% in the area $160^{\circ} \mathrm{E}-80^{\circ} \mathrm{W}, 10^{\circ} \mathrm{S}-10^{\circ} \mathrm{N}$, and regionally up to $50 \%$ ). This indicates that there are other factors besides the mean state changes in zonal SST and thermocline depth that influence the tropical Pacific interannual variability.

\section{Discussion and synthesis}

\subsection{Discussion in the context of observations and previous model studies}

Including light absorption by cyanobacteria in MPI-ESM has considerable effects on the simulated tropical climate mean state and variability. The net surface cooling effect induced by cyanobacteria in large parts of the tropics is rather counterintuitive. Theoretical considerations and a onedimensional model study (Sonntag and Hense, 2011) suggest a local surface warming would take place due to cyanobacteria light absorption. Also, satellite and in situ observations show a local warming effect due to the presence of cyanobacteria blooms (Kahru et al., 1993; Capone et al., 1998; Wurl et al., 2018). These observations, however, only represent snapshots of local heating events. Within the framework of the Earth system model used in this study, we show that on climatological timescale this surface warming effect prevails only in limited areas. In larger areas, on the contrary, the local surface warming effect of cyanobacteria transfers into a cooling effect on the climatological large scale due to the upwelling of cooler subsurface water. Cyanobacteria remotely affect regions relevant for biogeochemistry and climate variability and thus play a role on a larger scale than indicated by local observations and one-dimensional models.

A number of previous model studies concur with the relevance of the advective redistribution of heat and also diagnosed a cooling of equatorial SST caused by the presence of phytoplankton (Nakamoto et al., 2001; Sweeney et al., 2005; Anderson et al., 2007; Gnanadesikan and Anderson, 2009; Sonntag, 2013). In an idealized regional ocean model of the North Atlantic, Sonntag (2013) found that cyanobacteria locally heat the surface ocean, and nonlocally cool the equatorial SST due to advective processes - a result which qualitatively agrees with our study. The global model studies of Anderson et al. (2007) and Gnanadesikan and Anderson (2009) focused on similar regions as we do in this study. In line with our study, the authors found that explicitly accounting for water turbidity in off-equatorial regions (more precisely in the subtropical gyres and the eastern tropical regions overly- 
ing the oxygen minimum zones) leads to a surface cooling with similar patterns and effects on the mean climate state. Agreement between this study and the coupled model study by Gnanadesikan and Anderson (2009) on the sensitivity of the Walker and Hadley circulations, as well as precipitation patterns, to the changes in SST gives confidence to the robustness of our model results. Although Gnanadesikan and Anderson (2009) used a satellite climatology of chlorophyll, we applied a full biogeochemical model with interactive biogeophysical feedback. This ensures (1) a temporally varying chlorophyll field that is consistent with the model circulation field (due to nutrient and temperature limitation of phytoplankton growth that is to a large degree affected by the ocean circulation), (2) vertical variations in chlorophyll concentrations, and (3) the feedback from changes in physics on chlorophyll concentrations themselves. Furthermore, we were able to identify cyanobacteria to be the phytoplankton group that is largely responsible for the light absorption in the areas that are already considered important by Gnanadesikan and Anderson (2009). Cyanobacteria, able to fix $\mathrm{N}_{2}$, inhabit exactly the regions that have a regulative effect on tropical SST due to shading of the subsurface water that enters the shallow meridional cells. Moreover, cyanobacteria are positively buoyant and hence mainly concentrated in the upper $20 \mathrm{~m}$, where highest incoming radiation is present, and where effects on light absorption thus have strongest effects on temperature. Based on idealized model setups, Sonntag and Hense (2011) and Hense et al. (2017) already pointed out the potential necessity of "surface mat producers", such as positively buoyant cyanobacteria, to be included in Earth system models - a suggestion that we confirm in our study and furthermore quantify.

The cooling effect due to the water turbidity off-Equator was also stressed in global ocean-only studies. By considering the zonal momentum budget integrated over the mixed layer, the authors argue that stronger light absorption and related shallower MLDs in the regions off-Equator enhance the meridional transport and equatorial upwelling, which causes the simulated SST decrease at the Equator (Sweeney et al., 2005; Löptien et al., 2009; Park et al., 2014). In our coupled model setup, on the contrary, we show that the atmospheric feedback on ocean circulation largely outweighs the effect on upwelling induced by the change in the MLD and results, instead, in a decrease in upwelling strength in most parts. In the coupled system, the shading and hence cooling of the subsurface water that is eventually upwelled is responsible for the cooling effect, rather than an increase in upwelling strength itself. This discrepancy between the results of the ocean-only and the coupled model setup emphasizes the importance of using an Earth system model to study biogeophysical feedbacks in order to account for interactions between the different components of the Earth system.

We find that including the effect of light attenuation of phytoplankton on the ocean heat budget affects ENSO dynamics. This has already been suggested by previous model studies (e.g., Timmermann and Jin, 2002; Marzeion et al., 2005; Jochum et al., 2010). Many of the studies, however, attribute this effect to the presence of chlorophyll at the Equator. Our study indicates, in agreement with Anderson et al. (2009), that especially light absorption off-Equator plays a relevant role by modifying equatorial SST and thermocline depth. As cyanobacteria are strongly contributing to the light absorption strength off-Equator, they impose further complexity on ENSO dynamics that has not been taken into account in previous studies.

The use of an Earth system model with interactive biogeochemistry (instead of a chlorophyll climatology) furthermore allows us to study the feedback from phytoplankton-induced changes in climate on phytoplankton growth itself. The positive feedback (cyanobacteria promote their own growth due to the process of light absorption), which we find in some regions such as the subtropical bands of the Pacific Ocean, is in line with idealized model studies (Hense, 2007; Sonntag and Hense, 2011; Sonntag, 2013). In our simulations, however, the positive feedback is not acting locally via changes in temperature, as is the case in the studies mentioned above, but mainly via nonlocal processes, i.e. changes in the upwelling strength and hence the supply of nutrients. In large regions, these circulation changes lead to a decline in cyanobacteria concentrations in our simulation, which constitutes a negative feedback. Nutrient limitation of cyanobacteria growth is not included in abovementioned studies. This could explain the diverging results.

As seen in our sensitivity experiment, the patterns of change in climate properties induced by cyanobacteria are largely independent of their prescribed absorption strength (i.e., chlorophyll content). The magnitudes of the effects behave roughly linearly: a doubling of the absorption strength roughly doubles the anomalies for many of the analyzed quantities in large areas. This is not obvious, since many nonlinear processes are involved and the resulting local heating effect and nonlocal cooling effect do not necessarily need to add up to the same net effect (surface cooling or warming). The magnitudes of the effects are very sensitive to the prescribed strength of light absorption, i.e., the chlorophyll content of cyanobacteria. Since this parameter is not well constrained, there is a considerable potential range of impact induced by cyanobacteria light absorption. Chlorophyll concentrations are linearly derived from the cyanobacteria concentrations and thus have to be seen as a rough first-order approximation. In reality, chlorophyll content depends on a lot of factors, e.g., light conditions and temperature. For both applied parameters, 120 and $60 \mathrm{mgC}(\mathrm{mg} \mathrm{Chl})^{-1}$, the changes in the climate mean state and variability are significant compared to the internal variability in the model. The value of $60 \mathrm{mg} \mathrm{C}(\mathrm{mg} \mathrm{Chl})^{-1}$, as applied in PHY_CYAx2, is situated in the lower range of observations (i.e., in the upper range of chlorophyll contents) (e.g., Berman-Frank et al., 2001; Carpenter et al., 2004; Sathyendranath et al., 2009). The effects in this experiment can thus be roughly seen as an upper limit. 
(a)

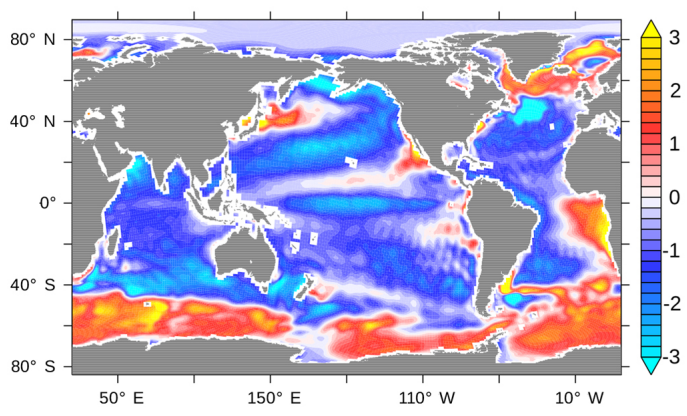

(b) $\triangle S S T$ (PHY_CYA - CTRL)

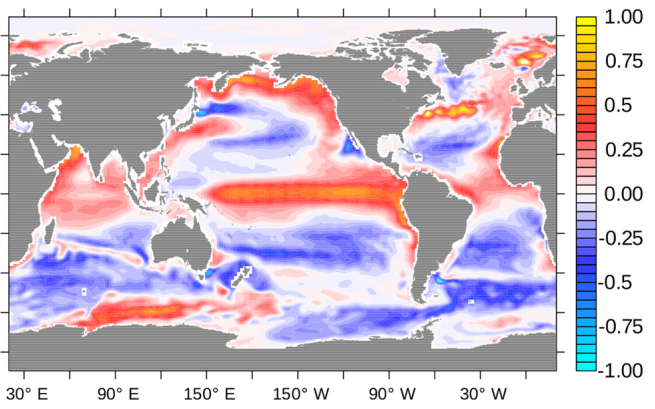

Figure 11. (a) SST (K) bias of CTRL compared to observations (PHC3 climatology). (b) Difference in SST (K) between PHY_CYA and CTRL.

On the other hand, cyanobacteria also contain pigments other than chlorophyll, like phycocyanin, which also absorb shortwave radiation in the visible range (e.g., Navarro Rodriguez, 1998), but are not accounted for in the model parameterization.

In addition to these uncertainties in the prescribed light absorption strength per cyanobacteria biomass, uncertainties in the cyanobacteria distribution itself impose uncertainties in the model results. As discussed in Paulsen et al. (2017), the model underestimates cyanobacteria concentrations in the North Atlantic subtropical gyre. Related to that, the surface cooling effect in the tropical Atlantic might be underestimated. On the other hand, the model might overestimate cyanobacteria concentrations in the tropical east Pacific, and thus also likely the cooling effect of the Pacific cold tongue. Despite these uncertainties in the details of the strength and patterns of the effects, the model results clearly indicate the potential of the phytoplankton group of cyanobacteria to play a relevant role in the Earth system.

\subsection{Implications for the Earth system model}

In this study, we focused on the impact of including prognostic cyanobacteria in addition to bulk phytoplankton in the dynamic biological shortwave heating on the climate system in MPI-ESM. In the following, we discuss our results in the context of the standard model version, which uses a globally uniform optical water type (our simulation CTRL), and in the context of observations. Figure 11a shows the SST bias of CTRL in comparison to observations (the Polar Science Center Hydrographic Climatology, PHC3, a blend of the Levitus et al., 1998, data with an updated data set for the Arctic from Steele et al., 2001). The changes in SST due to including the biogeophysical feedback from phytoplankton - bulk phytoplankton and cyanobacteria - on radiative heating only slightly improve the globally averaged mean SST bias (0.61 K in PHY_CYA compared to $0.62 \mathrm{~K}$ in CTRL) and the globally averaged root mean square error (1.35 K in PHY_CYA compared to $1.38 \mathrm{~K}$ in CTRL). In contrast, regional improvements are much more prominent. The tropical Pacific cold bias in PHY_CYA is reduced by $0.7 \mathrm{~K}$ (approx. 25\%) in comparison to CTRL (Fig. 11b). This furthermore implies a reduction of the precipitation bias in the western equatorial Pacific (not shown). The reduction of the cold bias in PHY_CYA compared to CTRL can be explained as follows: the globally constant water turbidity assumed in CTRL (which approximates to $0.44 \mathrm{mg} \mathrm{Chl} \mathrm{m}^{-3}$ ) overestimates the turbidity, and hence light absorption strength, within the clear-water regions of the oligotrophic subtropical gyres. In PHY_CYA, the phytoplankton-dependent water turbidity takes account of these low-chlorophyll areas. This leads to deeper- reaching light penetration within the subtropical gyres that results in a warming of the subsurface water within the shallow meridional overturning cells - the water that is eventually upwelled at the Equator. This equatorial surface warming effect due to clearer subtropical gyres was also seen in the study of Wetzel et al. (2006), in which a former version of MPI-ESM was used. Other studies (Patara et al., 2012, and references therein) also compared a model state with phytoplankton light absorption included (either from satellite chlorophyll or calculated in the biogeochemical model) against a reference state with globally constant water turbidity (either corresponding to zero chlorophyll or a constant nonzero chlorophyll value). Whether this leads to a warming, as in our study and in Wetzel et al. (2006), or to a cooling of equatorial SST strongly depends on the chosen reference state. If the reference turbidity within the subtropical gyres is lower than the prognostic value (e.g., zero chlorophyll; as in Gnanadesikan and Anderson, 2009), including the feedback leads to a cooling. In this case the higher chlorophyll values shade and hence cool the subsurface water that is upwelled at the Equator. If the reference turbidity within the subtropical gyres, on the other hand, is larger than the prognostic value (as is the case in our study and in Wetzel et al., 2006), including the feedback leads to a warming. The magnitudes of the anomalies are not directly comparable between the studies due to the different reference attenuation depths, which were used (11-43 m, see Patara et al., 2012, and references therein). All studies, including ours, however, agree 
that applying a phytoplankton-dependent light attenuation scheme instead of a globally uniform attenuation has considerable effects on the simulated model state. In our case, the changes improve some of the model biases, which emphasizes the relevance of including the biophysical feedback in the model. Omitting the effect of cyanobacteria (that means considering only the effect of bulk phytoplankton) results in even lower water turbidity within the subtropical gyres. The heating of the Pacific cold tongue and hence the improvement with respect to the Pacific SST bias compared to CTRL is even larger in PHY_ONLY compared to PHY_CYA. The strong regulative effect that cyanobacteria have on equatorial SST is important to note in this regard. Considering cyanobacteria in addition to bulk phytoplankton in the feedback, changes the anomaly by approx. 30\% (PHY_CYA CTRL: 0.7 K, PHY_ONLY - CTRL: $1.0 \mathrm{~K}$ ). This magnitude $(0.3 \mathrm{~K}, \mathrm{Fig} .2 \mathrm{a})$ is roughly half of approx. $0.75 \mathrm{~K}$, which is the difference that arises from running the model with a higher horizontal resolution (MR, global resolution of $0.4^{\circ}$; Jungclaus et al., 2013). The fact that in the equatorial region more realistic SST values are simulated when omitting light absorption by cyanobacteria might have two reasons. First, the surface chlorophyll of bulk phytoplankton in the subtropical gyres is slightly overestimated in comparison to satellite data (as mentioned in Sect. 3). This might lead to an overestimation of the water turbidity and hence an underestimation of the subsurface heating and the related equatorial surface warming. Second, model parameters were chosen to best represent the climate state in a model version without accounting for the biogeophysical feedback of light absorption. However, the fact that including cyanobacteria, which to our best knowledge should improve the represented distribution of light absorption, does regionally impair the model biases might indicate the demand for a retuning of certain model parameters, such as the ones related to vertical mixing.

Associated with a reduction of the SST bias of the Pacific cold tongue in the experiments with feedback included (PHY_ONLY, PHY_CYA, and PHY_CYAx2) compared to CTRL, the representation of the seasonality of tropical Pacific variability is also improved (Fig. 12). Although in CTRL the Niño 3.4 variability seems to have almost no seasonality, all simulations with feedback included establish a seasonal cycle in closer agreement with observations (HadISST1, Rayner et al., 2003). If the differences between the setups with and without cyanobacteria are significant against the large internal variability in the model (see blue bars in Fig. 12 that show \pm the standard deviation of eight 100-year periods of CTRL), it has to be tested in longer runs. The improvement of the seasonality of ENSO variability due to applying a phytoplankton-dependent instead of a globally uniform light attenuation was also found in Wetzel et al. (2006).

In contrast to the equatorial Pacific, where the inclusion of light absorption by cyanobacteria in addition to bulk phytoplankton does rather impair the SST bias, there are also

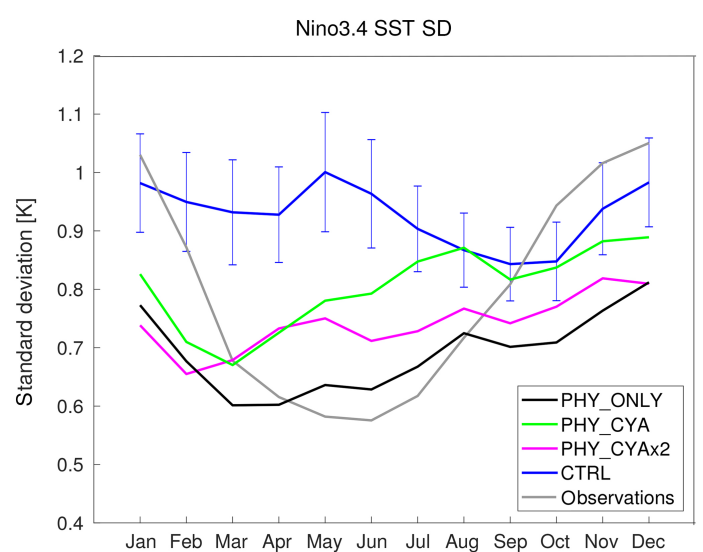

Figure 12. Seasonal cycle of the standard deviations of the Niño3.4 SST index (SST anomalies averaged over the area $5^{\circ} \mathrm{S}-5^{\circ} \mathrm{N}$, $170-120^{\circ} \mathrm{W}$ ) for the experiments PHY_ONLY (black), PHY_CYA (green), PHY_CYAx2 (purple), CTRL (blue), and observations (HadISST1; grey). The blue error bars on the blue curve show \pm the standard deviation of eight 100-year periods of CTRL.

regions where the SST bias is improved. In the coastal upwelling region of the southeastern tropical Atlantic, the cooling effect caused by including cyanobacteria reduces the coastal warm bias by $0.2-0.4 \mathrm{~K}$ in PHY_CYA compared to PHY_ONLY (relative to CTRL). This magnitude, and also the bias reduction in the equatorial Pacific of $0.7 \mathrm{~K}$ in PHY_CYA compared to CTRL mentioned above, are significantly larger than the internal variability in the model. They do, however, not completely eliminate the model biases. Other model uncertainties, like erroneous winds and an improper representation of stratocumulus clouds, still prevail (Jungclaus et al., 2013). Furthermore, the resolution of the atmospheric (Milinski et al., 2016) and the ocean general circulation model (Jungclaus et al., 2013) might induce biases. Nevertheless, our results show that the sensitivity of SST and climate to details in the spatial distribution of light absorption by marine biota indeed adds another level of complexity to the model which is largely independent of the model resolution and that should be taken into account in considerations of climate model biases.

\section{Summary and conclusions}

We use the Earth system model MPI-ESM to study the effects of light absorption by marine cyanobacteria on the tropical climate system. We find that accounting for prognostic cyanobacteria in addition to bulk phytoplankton in the attenuation depth of light has significant effects on the model's climate mean state and variability. In most regions, cyanobacteria induce a surface cooling on tropical SST on a climatological timescale in the order of $0.5 \mathrm{~K}$. This is because cyanobacteria biomass, located throughout the tropical and subtropical ocean, shades and hence cools the sub- 
surface water that is upwelled at the Equator and in eastern boundary upwelling regions. On climatological timescales, this advective process of bringing cooler subsurface water to the surface outweighs the direct local heating effect that was inferred from observations and idealized one-dimensional studies. The equatorial cooling leads to a weakening of the Hadley circulation, a westward shift (approx. $3.0^{\circ}$ longitude) of the Walker circulation, and changes in the precipitation patterns (up to $1.0 \mathrm{~mm} \mathrm{day}^{-1}$ ). Changes in ocean temperature and circulation feed back on cyanobacteria growth itself, imposing complex patterns of positive and negative feedback loops. Furthermore, the amplitude of the seasonal cycle of SST in areas where cyanobacteria are abundant is increased by approx. $25 \%$. Tropical Pacific variability is enhanced by roughly $20 \%$. The magnitudes of all effects are thereby sensitive to the prescribed strength of light absorption per cyanobacteria biomass. Doubling the chlorophyll content per cyanobacteria biomass (which results in a value in the upper range of observations) roughly doubles the magnitudes of most effects.

Accounting for the biologically induced radiative heating of phytoplankton (bulk phytoplankton and cyanobacteria) improves some of the model SST biases, e.g., the Pacific cold bias and the coastal warm bias in the southeastern tropical Atlantic, compared to the standard model version that applies a globally uniform light attenuation depth. The effects between including or not including cyanobacteria in the feedback demonstrate the sensitivity of the simulated climate mean state and variability to details in the distribution and representation of marine biota. In light of the uncertainties in the spatial distribution and light absorption strength of phytoplankton, the results stress the need for more observations to further constrain and better represent the effects of light absorption by marine biota in Earth system models. Our results indicate that the functional group of surface buoyant, $\mathrm{N}_{2}$-fixing cyanobacteria is important to be considered due to its regulative effect on tropical SST and climate.

Code and data availability. All simulations were performed at the German Climate Computing Center (DKRZ). The model code, primary data, and scripts needed to reproduce the analyses presented in this study are archived by the Max Planck Institute for Meteorology, and will be available by contacting publications@ mpimet.mpg.de.

Author contributions. HP developed the model code (with contributions from TI, KDS and IS), performed the experiments, and carried out the analyses (with contributions from all co-authors). HP prepared the manuscript with contributions from all co-authors.

Competing interests. The authors declare that they have no conflict of interest.
Acknowledgements. This study was part of the $\mathrm{PhD}$ thesis of Hanna Paulsen (Paulsen, 2018) and was funded by the International Max Planck Research School on Earth System Modelling. The authors would like to thank Michael Botzet for performing the simulation CTRL and Sebastian Sonntag as well as two anonymous referees for helpful comments on the manuscript.

The article processing charges for this open-access publication were covered by the Max Planck Society.

Edited by: Michel Crucifix

Reviewed by: two anonymous referees

\section{References}

Anderson, W., Gnanadesikan, A., Hallberg, R., Dunne, J., and Samuels, B.: Impact of ocean color on the maintenance of the Pacific Cold Tongue, Geophys. Res. Lett., 34, L11609, https://doi.org/10.1029/2007GL030100, 2007.

Anderson, W., Gnanadesikan, A., and Wittenberg, A.: Regional impacts of ocean color on tropical Pacific variability, Ocean Sci., 5, 313-327, https://doi.org/10.5194/os-5-313-2009, 2009.

Berman-Frank, I., Cullen, J. T., Shaked, Y., Sherrell, R. M., and Falkowski, P. G.: Iron availability, cellular iron quotas, and nitrogen fixation in Trichodesmium, Limnol. Oceanogr., 46, 12491260, 2001.

Bracher, A., Vountas, M., Dinter, T., Burrows, J. P., Röttgers, R., and Peeken, I.: Quantitative observation of cyanobacteria and diatoms from space using PhytoDOAS on SCIAMACHY data, Biogeosciences, 6, 751-764, https://doi.org/10.5194/bg-6-7512009, 2009.

Breitbarth, E., Oschlies, A., and LaRoche, J.: Physiological constraints on the global distribution of Trichodesmium - effect of temperature on diazotrophy, Biogeosciences, 4, 53-61, https://doi.org/10.5194/bg-4-53-2007, 2007.

Capone, D. G., Zehr, J. P., Paerl, H. W., Bergman, B., and Carpenter, E. J.: Trichodesmium, a globally significant marine cyanobacterium, Science, 276, 1221-1229, 1997.

Capone, D. G., Subramaniam, A., Montoya, J. P., Voss, M., Humborg, C., Johansen, A. M., Siefert, R. L., and Carpenter, E. J.: An extensive bloom of the diazotrophic cyanobacterium, Trichodesmium, in the Central Arabian Sea during the spring intermonsoon, Mar. Ecol. Prog. Ser., 172, 281-292, 1998.

Carpenter, E. J. and Romans, K.: Major role of the cyanobacterium Trichodesmium in nutrient cycling in the North Atlantic Ocean, Science, 254, 1356-1358, 1991.

Carpenter, E. J., Subramaniam, A., and Capone, D. G.: Biomass and primary productivity of the cyanobacterium Trichodesmium spp. in the tropical North Atlantic ocean, Deep-Sea Res. Pt. I, 51, 173-203, 2004.

Collins, M., An, S.-I., Cai, W., Ganachaud, A., Guilyardi, E., Jin, F.-F., Jochum, M., Lengaigne, M., Power, S., Timmermann, A., Vecchi, G., and Wittenberg, A.: The impact of global warming on the tropical Pacific Ocean and El Niño, Nat. Geosci., 3, 391-397, 2010.

Eppley, R. W.: Temperature and phytoplankton growth in the sea, Fish. Bull., 70, 1063-1085, 1972. 
Gnanadesikan, A. and Anderson, W. G.: Ocean water clarity and the ocean general circulation in a coupled climate model, J. Phys. Oceanogr., 39, 314-332, 2009.

Gregg, W. W., Casey, N. W., and McClain, C.: Recent trends in global ocean chlorophyll, Geophys. Res. Lett., 32, L03606, https://doi.org/10.1029/2004GL021808, 2005.

Großkopf, T., Mohr, W., Baustian, T., Schunck, H., Gill, D., Kuypers, M. M., Lavik, G., Schmitz, R. A., Wallace, D. W., and LaRoche, J.: Doubling of marine dinitrogen-fixation rates based on direct measurements, Nature, 488, 361-364, 2012.

Hense, I.: Regulative feedback mechanisms in cyanobacteria-driven systems: a model study, Mar. Ecol. Prog. Ser., 339, 41-47, 2007.

Hense, I., Stemmler, I., and Sonntag, S.: Ideas and perspectives: climate-relevant marine biologically driven mechanisms in Earth system models, Biogeosciences, 14, 403-413, https://doi.org/10.5194/bg-14-403-2017, 2017.

Ilyina, T., Six, K. D., Segschneider, J., Maier-Reimer, E., Li, H., and Núñez-Riboni, I.: Global ocean biogeochemistry model HAMOCC: Model architecture and performance as component of the MPI-Earth system model in different CMIP5 experimental realizations, J. Adv. Model. Earth Syst., 5, 287-315, 2013.

Jerlov, N.: Optical water types, Marine Optics, Elsevier Scientific, New York, 132-137, 1976.

Jochum, M., Yeager, S., Lindsay, K., Moore, K., and Murtugudde, R.: Quantification of the feedback between phytoplankton and ENSO in the Community Climate System Model, . Climate, 23, 2916-2925, 2010.

Johnson, K. S., Gordon, R. M., and Coale, K. H.: What controls dissolved iron concentrations in the world ocean? Authors' closing comments, Mar. Chem., 57, 181-186, 1997.

Jungclaus, J., Fischer, N., Haak, H., Lohmann, K., Marotzke, J., Matei, D., Mikolajewicz, U., Notz, D., and Storch, J.: Characteristics of the ocean simulations in the Max Planck Institute Ocean Model (MPIOM) the ocean component of the MPI-Earth system model, J. Adv. Model. Earth Syst., 5, 422-446, 2013.

Kahru, M., Lepppaenen, J.-M., and Rud, O.: Cyanobacterial blooms heating of the sea surface, in: Marine ecology progress series, Oldendorf, 101, 1-7, 1993.

Kara, A. B., Wallcraft, A. J., and Hurlburt, H. E.: A new solar radiation penetration scheme for use in ocean mixed layer studies: an application to the Black Sea using a fine-resolution Hybrid Coordinate Ocean Model (HYCOM), J. Phys. Oceanogr., 35, 13-32, 2005.

Karl, D., Michaels, A., Bergman, B., Capone, D., Carpenter, E., Letelier, R., Lipschultz, F., Paerl, H., Sigman, D., and Stal, L.: Dinitrogen fixation in the world's oceans, in: The Nitrogen Cycle at Regional to Global Scales, edited by: Boyer, E. W. and Howarth, R. W., Springer, Dordrecht, https://doi.org/10.1007/978-94-017-3405-9_2, 2002.

LaRoche, J. and Breitbarth, E.: Importance of the diazotrophs as a source of new nitrogen in the ocean, J. Sea Res., 53, 67-91, 2005.

Levitus, S., Boyer, T., Conkright, M., Johnson, D., Antonov, T. J., Stephens, C., and Gelfeld, R.: NOAA Atlas NESDIS 19, World Ocean Database 1998 Volume 2: Temporal Distribution of Mechanical Bathythermograph Profiles, US Gov. Printing Office, Washington, D.C., 286 pp., 1998.

Lewis, M. R., Cullen, J., and Platt, T.: Phytoplankton and thermal structure in the upper ocean: consequences of non-uniformity in chlorophyll profile, J. Geophys. Res.-Oceans, 88, 2565-2570, 1983.

Lewis, M. R., Carr, M.-E., Feldman, G. C., Esaias, W., and McClain, C.: Influence of penetrating solar radiation on the heat budget of the equatorial Pacific Ocean, Nature, 347, 543-545, 1990.

Löptien, U., Eden, C., Timmermann, A., and Dietze, H.: Effects of biologically induced differential heating in an eddy-permitting coupled ocean-ecosystem model, J. Geophys. Res.-Oceans, 114, C06011, https://doi.org/10.1029/2008JC004936, 2009.

Luo, Y.-W., Doney, S. C., Anderson, L. A., Benavides, M., BermanFrank, I., Bode, A., Bonnet, S., Boström, K. H., Böttjer, D., Capone, D. G., Carpenter, E. J., Chen, Y. L., Church, M. J., Dore, J. E., Falcón, L. I., Fernández, A., Foster, R. A., Furuya, K., Gómez, F., Gundersen, K., Hynes, A. M., Karl, D. M., Kitajima, S., Langlois, R. J., LaRoche, J., Letelier, R. M., Marañón, E., McGillicuddy Jr., D. J., Moisander, P. H., Moore, C. M., Mouriño-Carballido, B., Mulholland, M. R., Needoba, J. A., Orcutt, K. M., Poulton, A. J., Rahav, E., Raimbault, P., Rees, A. P., Riemann, L., Shiozaki, T., Subramaniam, A., Tyrrell, T., Turk-Kubo, K. A., Varela, M., Villareal, T. A., Webb, E. A., White, A. E., Wu, J., and Zehr, J. P.: Database of diazotrophs in global ocean: abundance, biomass and nitrogen fixation rates, Earth Syst. Sci. Data, 4, 47-73, https://doi.org/10.5194/essd-447-2012, 2012.

Manizza, M., Le Quéré, C., Watson, A. J., and Buitenhuis, E. T.: Ocean biogeochemical response to phytoplankton-light feedback in a global model, J. Geophys. Res.-Oceans, 113, C10010, https://doi.org/10.1029/2007JC004478, 2008.

Marsland, S. J., Haak, H., Jungclaus, J. H., Latif, M., and Röske, F.: The Max-Planck-Institute global ocean/sea ice model with orthogonal curvilinear coordinates, Ocean Model., 5, 91-127, 2003.

Marzeion, B., Timmermann, A., Murtugudde, R., and Jin, F.-F.: Biophysical feedbacks in the tropical Pacific, J. Climate, 18, 5870, 2005.

Meehl, G., Gent, P., Arblaster, J., Otto-Bliesner, B., Brady, E., and Craig, A.: Factors that affect the amplitude of El Nino in global coupled climate models, Clim. Dynam., 17, 515-526, 2001.

Milinski, S., Bader, J., Haak, H., Siongco, A. C., and Jungclaus, J. H.: High atmospheric horizontal resolution eliminates the wind-driven coastal warm bias in the southeastern tropical Atlantic, Geophys. Res. Lett., 43, 10455-10462, https://doi.org/10.1002/2016GL070530, 2016.

Mohanty, A., Satpathy, K., Sahu, G., Hussain, K., Prasad, M., and Sarkar, S.: Bloom of Trichodesmium erythraeum (Ehr.) and its impact on water quality and plankton community structure in the coastal waters of southeast coast of India, Indian J. Mar. Sci., 39, 323-333, 2010.

Murtugudde, R., Beauchamp, J., McClain, C. R., Lewis, M., and Busalacchi, A. J.: Effects of penetrative radiation on the upper tropical ocean circulation, J. Climate, 15, 470-486, 2002.

Nakamoto, S., Kumar, S. P., Oberhuber, J., Ishizaka, J., Muneyama, K., and Frouin, R.: Response of the equatorial Pacific to chlorophyll pigment in a mixed layer isopycnal ocean general circulation model, Geophys. Res. Lett., 28, 2021-2024, 2001.

Navarro Rodriguez, A. J.: Optical properties of photosynthetic pigments and abundance of the cyanobacterium Trichodesmium in 
the eastern Caribbean Basin, $\mathrm{PhD}$ thesis, University of Puerto Rico, Mayaguez, Puerto Rico, 1998.

Park, J.-Y., Kug, J.-S., Seo, H., and Bader, J.: Impact of bio-physical feedbacks on the tropical climate in coupled and uncoupled GCMs, Clim. Dynam., 43, 1811-1827, 2014.

Patara, L., Vichi, M., Masina, S., Fogli, P. G., and Manzini, E.: Global response to solar radiation absorbed by phytoplankton in a coupled climate model, Clim. Dynam., 39, 1951-1968, 2012.

Paulsen, H.: The effects of marine nitrogen-fixing cyanobacteria on ocean biogeochemistry and climate - an Earth system model perspective, PhD thesis, Universität Hamburg, Hamburg, 2018.

Paulsen, H., Ilyina, T., Six, K. D., and Stemmler, I.: Incorporating a prognostic representation of marine nitrogen fixers into the global ocean biogeochemical model HAMOCC, J. Adv. Model. Earth Syst., 9, 438-464, 2017.

Paulson, C. A. and Simpson, J. J.: Irradiance measurements in the upper ocean, J. Phys. Oceanogr., 7, 952-956, 1977.

Rayner, N., Parker, D. E., Horton, E., Folland, C., Alexander, L., Rowell, D., Kent, E., and Kaplan, A.: Global analyses of sea surface temperature, sea ice, and night marine air temperature since the late nineteenth century, J. Geophys. Res.-Atmos., 108, 4407, https://doi.org/10.1029/2002JD002670, 2003.

Reick, C., Raddatz, T., Brovkin, V., and Gayler, V.: Representation of natural and anthropogenic land cover change in MPI-ESM, J. Adv. Model. Earth Syst., 5, 459-482, 2013.

Reynolds, R. W., Smith, T. M., Liu, C., Chelton, D. B., Casey, K. S., and Schlax, M. G.: Daily high-resolution-blended analyses for sea surface temperature, J. Climate, 20, 5473-5496, 2007.

Sathyendranath, S., Stuart, V., Nair, A., Oka, K., Nakane, T., Bouman, H., Forget, M.-H., Maass, H., and Platt, T.: Carbon-to-chlorophyll ratio and growth rate of phytoplankton in the sea, Mar. Ecol. Prog. Ser., 383, 73-84, https://doi.org/10.3354/meps07998, 2009.

Schneck, R., Reick, C. H., and Raddatz, T.: Land contribution to natural $\mathrm{CO}_{2}$ variability on time scales of centuries, J. Adv. Model. Earth Syst., 5, 354-365, 2013.

SeaWiFS Project: SeaWiFS Global Monthly Mapped 9 km Chlorophyll a, Ver. 1., PO.DAAC, CA, USA, 2003.

Six, K. D. and Maier-Reimer, E.: Effects of plankton dynamics on seasonal carbon fluxes in an ocean general circulation model, Global Biogeochem. Cy., 10, 559-583, 1996.

Sonntag, S.: Modeling biological-physical feedback mechanisms in marine systems, $\mathrm{PhD}$ thesis, Universität Hamburg, Hamburg, 2013.

Sonntag, S. and Hense, I.: Phytoplankton behavior affects ocean mixed layer dynamics through biological-physical feedback mechanisms, Geophys. Res. Lett., 38, L15610, https://doi.org/10.1029/2011GL048205, 2011.
Speich, S., Blanke, B., and Cai, W.: Atlantic meridional overturning circulation and the Southern Hemisphere supergyre, Geophys. Res. Lett., 34, L23614, https://doi.org/10.1029/2007GL031583, 2007.

Steele, M., Morley, R., and Ermold, W.: PHC: A global ocean hydrography with a high-quality Arctic Ocean, J. Climate, 14, 2079-2087, 2001.

Stevens, B., Giorgetta, M., Esch, M., Mauritsen, T., Crueger, T., Rast, S., Salzmann, M., Schmidt, H., Bader, J., Block, K., Brokopf, R., Fast, I., Kinne, S., Kornblueh, L., Lohmann, U., Pincus, R., Reichler, T., and Roeckner, E.: Atmospheric component of the MPI-M Earth System Model: ECHAM6, J. Adv. Model. Earth Syst., 5, 146-172, 2013.

Strutton, P. G. and Chavez, F. P.: Biological heating in the equatorial Pacific: Observed variability and potential for real-time calculation, J. Climate, 17, 1097-1109, 2004.

Subramaniam, A., Brown, C. W., Hood, R. R., Carpenter, E. J., and Capone, D. G.: Detecting Trichodesmium blooms in SeaWiFS imagery, Deep-Sea Res. Pt. II, 49, 107-121, 2001.

Sweeney, C., Gnanadesikan, A., Griffies, S. M., Harrison, M. J., Rosati, A. J., and Samuels, B. L.: Impacts of shortwave penetration depth on large-scale ocean circulation and heat transport, J. Phys. Oceanogr., 35, 1103-1119, 2005.

Takahashi, T., Broecker, W. S., and Langer, S.: Redfield ratio based on chemical data from isopycnal surfaces, J. Geophys. Res.Oceans, 90, 6907-6924, 1985.

Taylor, A. H., Geider, R. J., and Gilbert, F. J.: Seasonal and latitudinal dependencies of phytoplankton carbon-to-chlorophyll a ratios: results of a modelling study, Mar. Ecol. Prog. Ser., 152, 51-66, 1997.

Timmermann, A. and Jin, F.-F.: Phytoplankton influences on tropical climate, Geophys. Res. Lett., 29, 2104, https://doi.org/10.1029/2002GL015434, 2002.

Westberry, T. K. and Siegel, D. A.: Spatial and temporal distribution of Trichodesmium blooms in the world's oceans, Global Biogeochem. Cy., 20, GB4016, https://doi.org/10.1029/2005GB002673, 2006.

Wetzel, P., Maier-Reimer, E., Botzet, M., Jungclaus, J., Keenlyside, N., and Latif, M.: Effects of ocean biology on the penetrative radiation in a coupled climate model, J. Climate, 19, 3973-3987, 2006.

Wurl, O., Bird, K., Cunliffe, M., Landing, W., Miller, U., Mustaffa, N., Ribas-Ribas, M., Witte, C., and Zappa, C.: Warming and inhibition of salinization at the ocean's surface by cyanobacteria, Geophys. Res. Lett., 45, 4230-4237, https://doi.org/10.1029/2018GL077946, 2018.

Zielinski, O., Llinás, O., Oschlies, A., and Reuter, R.: Underwater light field and its effect on a one-dimensional ecosystem model at station ESTOC, north of the Canary Islands, Deep-Sea Res. Pt. II, 49, 3529-3542, 2002. 